\title{
FRET monitoring of transcription factor activities in living bacteria
}

Pengchao Wang ${ }^{1,2}$, Guangming Zhang ${ }^{1}$, Zeling Xu ${ }^{1 \S}$, Zhe Chen ${ }^{1}$, Xiaohong Liu ${ }^{3}$, Chenyin Wang ${ }^{1}$, Chaogu Zheng ${ }^{1}$, Jiangyun Wang ${ }^{3 *}$, Hongmin Zhang ${ }^{2 *}$, Aixin Yan ${ }^{1 \star}$

1 School of Biological Sciences, The University of Hong Kong, Pokfulam Road, Hong Kong SAR, China.

2 Department of Biology, School of Life Sciences, Southern University of Science and Technology, Shenzhen 518055, Guangdong, China.

3 Institute of Biophysics, Chinese Academy of Sciences, Beijing, 15 Datun Road, Chaoyang District, Beijing 100101, China.

§, present address: Integrative Microbiology Research Centre, South China Agricultural University, Guangzhou, Guangdong, China

*: To whom correspondence should be addressed:

Jiangyun Wang: Institute of Biophysics, Chinese Academy of Sciences, Beijing, 15 Datun Road, Chaoyang District, Beijing 100101, China; jwang@ibp.ac.cn

Hongmin Zhang: Department of Biology, School of Life Sciences, Southern University of Science and Technology, Shenzhen 518055, Guangdong, China; zhanghm@sustech.edu.cn

Aixin Yan: School of Biological Sciences, The University of Hong Kong, Pokfulam Road, Hong Kong SAR, China; ayan8@hku.hk; Tel. (852) 22990864; Fax. (852) 25599114. 


\begin{abstract}
Bacteria adapt to the constantly changing environments largely by transcriptional regulation through the activities of various transcription factors (TFs). However, techniques that monitor the in situ TF-promoter interactions in living bacteria are lacking. Herein, we developed a whole-cell TF-promoter binding assay based on the intermolecular Förster resonance energy transfer (FRET) between a fluorescent unnatural amino acid CouA which is genetically encoded into defined sites in TFs and the live cell fluorescent nucleic acid stain SYTO 9. We show that this new FRET pair monitors the intricate TF-promoter interactions elicited by various types of signal transduction systems with specificity and sensitivity. Furthermore, the assay is applicable to identify novel modulators of the regulatory systems of interest and monitor TF activities in bacteria colonized in C. elegans. In conclusion, we established a tractable and sensitive TF-promoter binding assay in living bacteria which not only complements currently available approaches for DNA-protein interactions but also provides novel opportunities for functional annotation of bacterial signal transduction systems and studies of the bacteria-host interface.
\end{abstract}

\title{
Introduction
}

Pathogenic bacteria encounter diverse environmental and physiological stresses in their natural habitats and during infection of the human hosts, such as oxygen fluctuation, nutrient scarce, hyperosmolarity, bile salts, bactericidal agents, etc. (1). To survive these hostile environments, pathogens have developed exquisite regulatory systems that not only sense the diverse signals but also trigger specific responses by altering gene expression (1-3). In bacteria, stress adaption is largely achieved by regulation at transcriptional level through the activities of various transcription factors (TFs) (4). Efficient and specific binding of TFs to their targeting promoters is the key for the success of stress adaptation and survival of the pathogens. However, a method to monitor the in situ TF-promoter binding in living bacteria, especially in the complex cellular environment under stresses, is lacking.

Owing to its importance in transcription regulation and stress adaptation, several methods to 
bioRxiv preprint doi: https://doi.org/10.1101/2022.01 14.476424 this version posted January 15,2022 . The copyright holder for this preprint (which was not certified by peer review) is the author/funder, who has granted bioRxiv a license to display the preprint in perpetuity. It is made available under aCC-BY-NC-ND 4.0 International license.

characterize the TF-promoter interactions, including both in vitro and in vivo, low- and high throughput, have been developed. In vitro methods include the well-established electrophoretic mobility shift assay (EMSA) (5,6), filter-binding assay (7), DNA foot-printing (8), isothermal titration calorimetry (ITC) (9), and surface plasmon resonance (SPR) (10) etc. that detect the direct binding of TF to its promoters qualitatively and quantitatively. However, a common drawback of these in vitro methods is that the protein and DNA concentrations utilized are usually higher than those in the cell and the DNA fragment is in naked form instead of the compact chromatin state in the cell. Hence, these methods are unable to precisely recapitulate the TF-promoter recognition and binding during the stress adaptation processes in living cells. The high throughput approaches developed in recent years such as chromatin immunoprecipitation coupled with sequencing (ChIP-Seq) and systematic evolution of ligands by exponential enrichment (SELEX) are capable of capturing the TF-promoter binding in vivo occurred under specific culture conditions $(11,12)$. However, they are generally employed to provide a snapshot of the TF binding sites in the entire genome of bacterial cells and the techniques rely on high throughput sequencing facilities, limiting their widespread applications and accessibilities. Furthermore, all these currently available methods suffer from a limited dynamic range of the TF-promoter interactions detected and are incapable of monitoring the TF-promoter binding elicited by transient or indirect signals present in living bacteria and at the bacteria host interface.

Förster resonance energy transfer (FRET) measurement is an extensively employed strategy to monitor conformational changes and associations between macromolecules in living organisms in real time (1315). It measures the dipole-dipole energy transfer between two fluorophores (a donor and an acceptor) that are attached to the same biomolecule (intramolecular FRET) or a pair of biomolecules of interests (intermolecular FRET), respectively, when they are in nanoscale proximity and have spectral overlap. 
bioRxiv preprint doi: https://doi.org/10.1101/2022.01 14.476424 this version posted January 15,2022 . The copyright holder for this preprint (which was not certified by peer review) is the author/funder, who has granted bioRxiv a license to display the preprint in perpetuity. It is made available under aCC-BY-NC-ND 4.0 International license.

Since the efficiency of the energy transfer is reversely correlated to the six power of the distance of the two fluorophores (16), FRET measurement reliably indicates the close proximity and alignment of the macromolecule linker (intramolecular FRET) or macromolecule pairs (intermolecular FRET) onto which the donor and acceptor fluorophores are attached with extreme sensitivity and accuracy. Furthermore, FRET spectroscopy and microscopy represents almost the most simple and accessible form of superresolved optical measurement (17-19), enabling quantitative and in situ characterization of macromolecule associations both in vitro and in living organisms. Attempts to measure protein-DNA interaction by FRET technique have been reported (20-23). However, majority of these assays were developed for measurement of protein-DNA fragment interactions in vitro due to the simplicity of fluorescent labeling of synthetic DNA fragments and recombinant proteins. Furthermore, intramolecular FRET in which the donor and acceptor fluorophores were dually attached to a single biomolecule was often employed and protein-DNA interaction was inferred by the conformational changes of this fluorescent labeled DNA or protein component $(23,24)$. These approaches are indirect and inapplicable to monitor the TF-promoter DNA binding in the complex cellular environments in living cells. Intermolecular FRET, on the other hand, is ideal to report the direct interaction of two macromolecules onto which the FRET fluorophore pairs are attached separately. Despite this advantage, an intermolecular FRET-based assay to detect macromolecule interactions in living cells is technically challenging due to the exquisite sensitively of FRET which requires both the close proximity and optimal alignment of the donor and acceptor pairs and the necessity of controlling the ratio of the donor and acceptor fusions to minimize background noise.

In this study, we design an intermolecular FRET-based assay system to monitor TF-promoter binding in living bacteria by employing a pair of bright fluorophores to separately label the TF protein and cellular 
bioRxiv preprint doi: https://doi.org/10.1101/2022.01.14.476424 this version posted January 15,2022 . The copyright holder for this preprint (which was not certified by peer review) is the author/funder, who has granted bioRxiv a license to display the preprint in perpetuity. It is made available under aCC-BY-NC-ND 4.0 International license.

chromosome DNA. To overcome technical challenges of establishing an intermolecular FRET sensor in live cells, we introduce fluorescence property into TF proteins through genetic encoding of a fluorescent unnatural amino acid (FUAA) at a defined site, i.e., location of TF proteins, i.e., the DNAbinding domain, as the donor fluorophore (25), and employ the cell permeable nucleic acid dye SYTO 9 which is highly selective to DNA molecules (extinction coefficient $>50,000 \mathrm{~cm}^{-1} \mathrm{M}^{-1}$ ) with a substantial quantum yield (0.58) as the acceptor fluorophore to stain the cellular chromosome DNA. (26). To establish a complementary fluorophore that pairs with SYTO 9, we compared the fluorescence properties of a handful of FUAAs with available aminoacyl-tRNA synthetase (aaRS)-tRNA pairs which are required for genetic incorporation (Table S1) (26-31). An FUAA with the 7-hydroxycoumarin fluorophore, L-(7-hydroxycoumarin-4-yl) ethylglycine (CouA), which is characterized by an emission spectrum peaked at $450 \mathrm{~nm}$ with a high quantum yield (0.63) (27) displays the desired properties for spectral overlap with the DNA-bound SYTO 9 (absorption peak 500nm). Moreover, the fluorophore affords a large Stokes shift (27) (Fig. S1) which is ideal for intermolecular FRET sensors due to free or minimal cross-excitation. The theoretical Förster radius of this new FRET pair (CouA-SYTO 9) is calculated to be $52.5 \AA$ (Fig. S1) which should allow the occurrence of FRET when the distance between the two fluorophores is in the range of $\sim 25-75 \AA$.

Herein, we first validated the applicability and efficiency of the new FRET pair CouA-SYTO 9 to report the intricate TF-promoter interactions between a canonical TF protein CueR (CueR-F58CouA) and SYTO 9-stained targeting promoter fragment $\mathrm{P}_{\text {copA }}$ in vitro. An intermolecular FRET-based whole-cell assay employing E. coli cells expressing CueR-F58CouA in the presence of SYTO 9 stain was then established to measure the CueR-promoter interaction in living bacteria in response to copper $(\mathrm{Cu})$ stress. Specificity of the assay was verified by the abolishment of FRET upon mutating the key arginine 
residues responsible for promoter binding in CueR or deleting its target promoters $\mathrm{P}_{\text {copA }}$ and $\mathrm{P}_{\text {cueo }}$ in the chromosome of E. coli. Followingly, the assay was extended to monitor the signal transduction and transcription regulation elicited by two-component systems and was employed to identify novel signals that modulate the regulatory systems of interest. Its application to report the TF-promoter binding in $E$. coli colonized in the C. elegans host was also demonstrated.

\section{Materials and Methods}

\section{Construction of plasmid for TF protein expression}

DNA fragment encoding the TF protein of interest was obtained by polymerase chain reaction (PCR) amplification using genomic DNA of E. coli MG1655 as the template. Primers used are listed in Table S2. The fragment and pET28a plasmid were both digested with $\mathrm{Ncol}$ and Xhol for $3 \mathrm{hrs}$ at $37^{\circ} \mathrm{C}$. Following purification using the MiniBEST agarose gel DNA extraction kit (TaKaRa), the digested DNA fragment and pET28a were ligated using the quick ligation kit (NEB). The resulting construct was selected on LB agar plates supplemented with kanamycin $(20 \mu \mathrm{g} / \mathrm{ml})$ and was verified by DNA sequencing (BGI, Shenzhen). All plasmids constructed are listed in the supplementary Table S3.

\section{Amber codon mutation of selected CouA incorporation sites}

Each of the selected amino acid sites for CouA incorporation was mutated to a TAG amber codon by site-directed mutagenesis PCR. PCR was conducted using a pair of primers for the desired mutagenesis (Table S2) and pET28a-cueR, pET28a-basR or pET28a-phoP plasmid as the template. PCR product was purified using MiniBEST agarose gel DNA extraction kit (TaKaRa). Following Dpnl digestion of the template at room temperature overnight, the PCR product was transformed into E. coli DH5a. The transformants were recovered on LB agar plates supplemented with kanamycin $(20 \mu \mathrm{g} / \mathrm{ml})$ 
at $37^{\circ} \mathrm{C}$ overnight. Colonies recovered were verified by DNA sequencing (BGI, Shenzhen).

\section{CRISPR/Cas9-mediated deletion of $P_{\text {copA }}$ and $P_{\text {cueo }}$ in E. coli chromosome}

Deletion of chromosomal copA and cueO promoter regions were achieved employing a CRISPR/Cas9mediated approach developed by Zhao et al. (32) with modifications. E. coli BL21 (DE3) was electrotransformated with pCAGO plasmid which contains both SpCas9 and $\lambda$-RED to obtain BL21pCAGO. A single colony of the resulting transformant was inoculated into LB medium supplemented with ampicillin $(100 \mathrm{mg} / \mathrm{ml})$ and grew overnight at $30^{\circ} \mathrm{C} .100 \mu \mathrm{l}$ of the overnight culture was inoculated into $10 \mathrm{ml}$ fresh culture medium and cells were grown at $30^{\circ} \mathrm{C}$ with IPTG $(0.1 \mathrm{mM})$ induction to $\mathrm{OD}_{600}$ as 0.6 . The cells were collected and washed with cold $\mathrm{ddH}_{2} \mathrm{O}$ for three times, generating competent cells for electroporation. An aliquot comprising $100 \mu \mathrm{l}$ competent cells was mixed with $800 \mathrm{ng}$ of the editing-cassette which encompasses 40 bp of upstream-homologous arm of cueO promoter region (74 to -1) followed by the chloramphenicol resistant gene, the N20PAM sequence (GTCCATCGAACCGAAGTAAGG), the other same upstream-homologous arm of cueO promoter region, and 40bp downstream-homologous arm, in a $2 \mathrm{~mm}$ Gene Pulser cuvette (Bio-Rad) and was subjected to electroporation at $2.3 \mathrm{kV}$. Following recovering the transformants by cultivation in LB medium for 2 hrs at $30^{\circ} \mathrm{C}$, the mixture was spread onto LB agar plate supplemented with ampicillin (100mg/ml), chloramphenicol $(25 \mathrm{mg} / \mathrm{ml})$, and $1 \%$ glucose (to avoid the background expression of the Cas9 protein). Single colonies were collected and verified by colony PCR to obtain an authentic clone in which the cueO promoter region is replaced by the editing-cassette. The confirmed colony was inoculated into LB medium supplemented with ampicillin $(100 \mathrm{mg} / \mathrm{ml})$, IPTG $(0.1 \mathrm{mM})$, and L-arabinose $(0.2 \%)$ at $30^{\circ} \mathrm{C}$ overnight to enable expression of SpCas9 and the $\lambda$-RED recombinase. The cells were 
bioRxiv preprint doi: https://doi.org/10.1101/2022.01.14.476424 this version posted January 15,2022 . The copyright holder for this preprint (which was not certified by peer review) is the author/funder, who has granted bioRxiv a license to display the preprint in perpetuity. It is made available under aCC-BY-NC-ND 4.0 International license.

then spread on LB agar plates supplemented with ampicillin $(100 \mathrm{mg} / \mathrm{ml})$. Following colony PCR, desired colonies containing deletion of the promoter of cueO gene (AY7037) were verified by DNA sequencing (BGI, Shenzhen). Deletion of the promoter region (-80 to -1) of copA gene in AY7038 was conducted following the same procedures except for the editing cassette sequence which encompasses $40 \mathrm{bp}$ of upstream-homologous arm of $\operatorname{copA}$ promoter region followed by the chloramphenicol resistant gene, the N2OPAM sequence, the other same $40 \mathrm{bp}$ upstream-homologous arm of copA promoter region, and $40 \mathrm{bp}$ downstream-homologous arm. After obtaining all desired genome modifications, the editing plasmid was cured by growing the resulting cells at $42^{\circ} \mathrm{C}$ for $48 \mathrm{hrs}$.

\section{CouA incorporation in TF proteins and purification of the resulting protein}

The pET28a-cueR-F58TAG plasmid expressing a C-terminal His6-tagged CueR-F58TAG was cotransformed with pEVOL-CouRS that contains tRNAcuA and aminoacyl tRNAcuA synthetase (27) into $E$. coli BL21 (DE3). Transformants were grown on an LB agar plate supplemented with kanamycin (20 $\mu \mathrm{g} / \mathrm{ml}$ ) and chloramphenicol $(25 \mu \mathrm{g} / \mathrm{ml})$. A single colony of the resulting transformant was inoculated into LB medium supplemented with kanamycin $(20 \mu \mathrm{g} / \mathrm{ml})$ and chloramphenicol $(25 \mu \mathrm{g} / \mathrm{ml})$ and grew overnight at $37^{\circ} \mathrm{C} .1 \mathrm{ml}$ of the overnight culture was inoculated into $100 \mathrm{ml}$ of fresh culture medium and cells were grown at $37^{\circ} \mathrm{C}$ to $\mathrm{OD}_{600}$ as 1.0 . Following induction of protein expression with $0.04 \%$ arabinose and 0.5 mM IPTG in the presence of $1 \mathrm{mM}$ CouA (Shanghai VastPro Technology) for $12 \mathrm{hrs}$ at $30^{\circ} \mathrm{C}$, cells were harvested by centrifugation $(4000 \times \mathrm{g})$ for $15 \mathrm{~min}$. Cell pellet was resuspended in 10 $\mathrm{ml}$ lysis buffer (20 mM Tris-HCl, $\mathrm{pH}$ 8.0, $2 \mathrm{M} \mathrm{NaCl}$ ) and was subject to sonication on ice. Cell debris was removed by centrifugation at $13000 \times \mathrm{g}$ at $4^{\circ} \mathrm{C} .1 \mathrm{ml}$ Ni-NTA agarose (QIAGEN) was added to the collected supernatant and the mixture was gently shaken at $4^{\circ} \mathrm{C}$ for $2 \mathrm{hrs}$. Supernatant was removed by gravity column and agarose beads were washed with $50 \mathrm{ml}$ washing buffer $(20 \mathrm{mM}$ Tris- $\mathrm{HCl}, \mathrm{pH}$ 8.0, 2 
$\mathrm{M} \mathrm{NaCl}, 30 \mathrm{mM}$ imidazole). CueR-F58CouA protein was eluted using elution buffer (20 mM Tris- $\mathrm{HCl}$, pH 8.0, $2 \mathrm{M} \mathrm{NaCl}, 500 \mathrm{mM}$ imidazole). Purified protein was subsequently suspended in the buffer for binding assay $(20 \mathrm{mM}$ Tris- $\mathrm{HCl}, \mathrm{pH} 8.0,150 \mathrm{mM} \mathrm{NaCl})$ by buffer exchange through ultrafiltration at $4000 \times g$.

\section{Verification of CouA incorporation by SDS-PAGE and LC-MS/MS}

Purified CueR-F58CouA, BasR-D182CouA, and PhoP-A182CouA protein were analyzed by SDSPAGE electrophoresis. $15 \mu$ l of each sample was loaded onto SDS-PAGE (Bio-Rad Mini-PROTEAN Tetra). Following electrophoresis for 60min at room temperature, the gel was imaged under UV transilluminator (UVP) to record fluorescent band and then stained with Coomassie blue. The image of stained gel was recorded by Gel Doc ${ }^{\mathrm{TM}} \mathrm{XR}+$ imaging system (Bio-rad). Gel slices corresponding to CueR-F58CouA (16.2 kDa), BasR-D182CouA (26.1 kDa), and PhoP-A182CouA (26.6 kDa) was excised and sent for LC/ESI-MS/MS (Dionex UltiMate 3000 RSLC nano Liquid Chromatography \& Orbitrap Fusion Lumos Tribrid Mass Spectrometer).

\section{TF protein structure prediction (PhoP as an example)}

The 3D structure of transcription factor or response regulator protein of two-component systems was predicted via I-TASSER server (https://zhanglab.ccmb.med.umich.edu/l-TASSER/). Amino acid sequences of these proteins were submitted to the server to yield a prediction on the secondary structure, solvent accessibility and normalized B-factor. Ten templates which display the highest significance in the threading alignments from the PDB library were then identified. The server calculated two feasible models, model 1 and model 2 based on the ten templates. The resulting prediction with a higher confidence score (C-score), i.e., model 1 (0.95) in the case of the PhoP protein, was adopted to 
illustrate the structure of the protein in a PDB file.

\section{Phosphorylation assay using Phos-tag SDS-PAGE}

In vivo phosphorylation of BasR was examined using phos-tag SDS-PAGE following our previous description with minor modifications (33). E. coli MG1655 cell harboring pET28a-pBAD-basR-FLAG (AY7068) was inoculated into MOPS minimum medium supplemented with kanamycin $(20 \mu \mathrm{g} / \mathrm{ml})$ and grew overnight at $37^{\circ} \mathrm{C} .50 \mu \mathrm{l}$ of the overnight culture was inoculated into $5 \mathrm{ml}$ fresh MOPS medium and grew at $37^{\circ} \mathrm{C}$ for $4 \mathrm{hrs}$. Expression of BasR was induced with $1 \mathrm{mM}$ arabinose for $1 \mathrm{hr}$. The cells were collected by centrifugation at $4000 \times \mathrm{g}$. The cells were washed with MOPS medium supplemented with $0.1,0.5$, or $1 \mathrm{mM} \mathrm{FeCl}_{3}$ twice and then cultivated in the corresponding medium for $1 \mathrm{hr} .1 \mathrm{ml}$ of cells with $\mathrm{OD}_{600} \sim 0.5$ was collected for the subsequent analysis. The cell was washed with cold PBS twice and resuspended in $200 \mu \mathrm{l}$ sample buffer (13 mM Tris, 0.2\% SDS, 5\% glycerol, $0.004 \%$ bromophenol blue, $\mathrm{pH}$ 6.8) before being subjected to cell lysis by sonication. Following centrifugation at $13000 \mathrm{rpm}$ for $10 \mathrm{~min}$ at $4^{\circ} \mathrm{C}, 25 \mu \mathrm{l}$ of the sample was loaded onto the $10 \%$ Tris-Gly polyacrylamide gel containing $25 \mathrm{mM}$ Phos-tag Acrylamide (Wako) and $50 \mathrm{mM} \mathrm{MnCl}_{2}$. The samples were separated by electrophoresis for $2 \mathrm{hrs}$ at $4^{\circ} \mathrm{C}$. The gel was then washed with $50 \mathrm{ml}$ transfer buffer containing $10 \mathrm{mM}$ EDTA for $20 \mathrm{~min}$ to remove residual $\mathrm{Mn}^{2+}$. Proteins on the gel were transferred onto a PVDF membrane. The membrane was blocked with 5\% non-fat milk in TBST buffer and was incubated subsequently with monoclonal ANTI-FLAG ${ }^{\circledR}$ M2 antibody (Sigma) and goat anti-mouse IgG (H+L)-HRP conjugate (Bio-rad). To detect FLAG-tagged protein bands, the membrane was submerged in the ECL Plus Western Blotting Detection Reagents (GE Healthcare) for 2 min and then subjected to the imaging system (UVITEC Cambridge) to record signals. 
bioRxiv preprint doi: https://doi.org/10.1101/2022.01 14.476424 ${ }^{\circ}$ this version posted January 15,2022 The copyright holder for this preprint (which was not certified by peer review) is the author/funder, who has granted bioRxiv a license to display the preprint in perpetuity. It is made available under aCC-BY-NC-ND 4.0 International license.

The 185bp promoter region of copA gene ( $\mathrm{P}_{\text {copA }},-178$ to $\left.+7 \mathrm{bp}\right)$ was obtained by PCR using genomic DNA of E. coli MG1655 as the template. An additional DNA fragment (139 bp) located in the coding region of the cueR gene was also obtained by PCR and served as the negative control for the in vitro binding assay. $10 \mu \mathrm{M}$ purified CueR-F58CouA was mixed with $0.3 \mu \mathrm{M}$ DNA fragment ( $\mathrm{P}_{\text {copA }}$ or Frag 1$)$ in $100 \mu \mathrm{l}$ assay buffer (20 mM Tris- $\mathrm{HCl}, 150 \mathrm{mM} \mathrm{NaCl}, \mathrm{pH}$ 8.0) and was incubated at room temperature for 15min. 15uL SYTO $9\left(50 \mu \mathrm{M}\right.$ in $\left.\mathrm{ddH}_{2} \mathrm{O}\right)$ was then added (final concentration $\left.7.5 \mu \mathrm{M}\right)$. Following incubation for 15 min in dark, fluorescence spectrum of the mixture was recorded using Thermo Scientific Varioskan ${ }^{\circledR}$ Flash spectral scanning multimode reader.

\section{Whole-cell FRET measurement to detect in vivo CueRcouA - promotersyto 9 binding}

A fresh single colony of $E$. coli cell (AY3660) harboring pET28a-cueR-F58TAG and pEVOL-CouRS was inoculated into LB medium supplemented with kanamycin $(20 \mu \mathrm{g} / \mathrm{ml})$ and chloramphenicol $(25 \mu \mathrm{g} / \mathrm{ml})$ and grew overnight at $37^{\circ} \mathrm{C} .75 \mu \mathrm{l}$ of the overnight culture was inoculated to $7.5 \mathrm{ml}$ fresh medium to subculture the bacteria. Following culturing at $37^{\circ} \mathrm{C}$ for $4 \mathrm{hrs}$, CouA incorporation and expression of CueR-F58CouA (or CueR-T27CouA, CueR-Y39CouA, CueR-Q74CouA) was induced mildly by supplementing $0.5 \mathrm{mM} \mathrm{IPTG}, 0.4 \%$ arabinose and $1 \mathrm{mM}$ CouA at $37^{\circ} \mathrm{C}$ for $4 \mathrm{hrs}$. Metal ion (stimulating signals) of $0.1 \mathrm{mM} \mathrm{CuSO}_{4}, 0.02 \mathrm{mM} \mathrm{MnCl}_{2}$, or $0.02 \mathrm{mM} \mathrm{NiCl}_{2}$ (final concentration) was also added. Approximately $8 \times 10^{9}$ cells were harvested and washed twice with PBS buffer. Following centrifugation at $4000 \times \mathrm{g}$ for $15 \mathrm{~min}$ at $4^{\circ} \mathrm{C}$, cell pellet was resuspended in $600 \mu \mathrm{l}$ of PBS. $85 \mu \mathrm{l}$ of the suspension was added in each of 6 wells ( 3 wells for control and 3 wells for experimental group) on a 96-well black plate preloaded with $15 \mu \mathrm{l}$ of $50 \mu \mathrm{M}$ SYTO 9 and was incubated for $15 \mathrm{~min}$ at room temperature in the dark before being subjected to fluorescence recording. 


\section{In vivo BasR couA - promotersyto 9 binding assay}

Plasmid pET28a-pBAD-basR-D182TAG, G137TAG, E146TAG or S167TAG was co-transformed with pEVOL-CouRS into E. coli MG1655 $\triangle$ basR strain, resulting in AY7064, AY7065, AY7066 and AY7067 constructs, respectively. Culture conditions for mild protein induction and CouA incorporation were

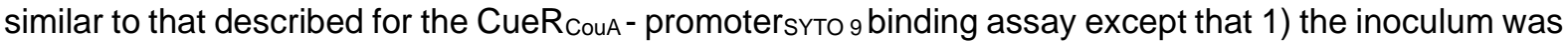
cultured in MOPS minimum medium at $37^{\circ} \mathrm{C}$ for $4 \mathrm{hrs}$ before induction; 2 ) the induction was conducted in the presence of $0.9 \%$ arabinose and $1 \mathrm{mM}$ CouA at $37^{\circ} \mathrm{C}$ for $5 \mathrm{hrs}$. Approximately $3.5 \times 10^{10}$ cells were harvested and washed twice with fresh MOPS medium. The cells were resuspended in MOPS medium supplemented with $0.5 \mathrm{mM} \mathrm{FeCl}_{3}$ as the inducing signal for the BasSR TCS system and shake for $1 \mathrm{hr}$ $37^{\circ} \mathrm{C}$. After centrifugation at $4000 \times \mathrm{g}$ for $15 \mathrm{~min}$ at $4^{\circ} \mathrm{C}$, cell pellet was resuspended in $600 \mu \mathrm{l}$ of PBS. The sample preparation and fluorescence spectrum recording were performed as described in the CueRcouA - promotersyto g binding assay.

\section{In vivo PhoP ${ }_{\text {couA }}$ - promotersyto 9 binding assay}

The pET28a-phoP-S137TAG, D145TAG or A182TAG plasmid was co-transformed with pEVOL-CouRS into E. coli BL21 (DE3), resulting in AY3707, AY3708, and AY3709 constructs, respectively. Culture conditions for mild protein induction and CouA incorporation were similar to that described for the CueRcouA-promoter DNAsyto 9 binding assay except that 1) the induction was conducted in the presence of $0.5 \mathrm{mM} \mathrm{IPTG}, 0.4 \%$ arabinose and $1 \mathrm{mM}$ CouA at $37^{\circ} \mathrm{C}$ for $5 \mathrm{hrs}$, and 2) the stimulants for the PhoPQ system were applied prior to fluorescence signal recording rather than during the induction. Approximately $6 \times 10^{9}$ cells were harvested and were subjected to sample preparation. Following incubating $85 \mu$ l of cell suspension containing mildly induced PhoP-CouA protein and $15 \mu$ of SYTO 9 $(50 \mu \mathrm{M})$ at room temperature for $15 \mathrm{~min}$ in the dark, different stimuli was added in the buffer. $1 \mathrm{mM}$ of 
$\mathrm{MgCl}_{2}$ was added to the cell suspension before adding other stimulants. EDTA, polymyxin $\mathrm{B}$, tryptophan, indole, IAA, gentamycin was added at the designated concentrations in the text. The suspension is subjected to fluorescence spectrum recording as described above. Zero-time is defined as the fluorescence of the assay system recorded immediately following the addition of stimulants.

\section{Fluorescence spectroscopy and FRET effect quantification}

Fluorescence spectra of the assay suspension described above were recorded using Thermo Scientific Varioskan ${ }^{\circledR}$ Flash spectral scanning multimode reader at $25^{\circ} \mathrm{C}$. The excitation wavelength was fixed at $360 \mathrm{~nm}$, and the scanning wavelength was recorded from 400 to $550 \mathrm{~nm}$. Degree of the FRET effect was quantified by the ratio of

$$
F_{E}=I_{A} / I_{D}
$$

where $I_{A}$ is the fluorescence intensity of CouA at $500 \mathrm{~nm}$, and $I_{D}$ is the fluorescence intensity at 450 $\mathrm{nm}$.

The Förster radius $R_{0}$ is the Förster distance which is the distance between the FRET donor and acceptor when the energy transfer efficiency is $50 \% . R_{0}$ is calculated from the equation (34):

$$
\mathrm{R}_{0}^{6}=\left(\frac{9000(\ln 10) \cdot K^{2} \cdot Q_{D} \cdot J(\lambda)}{128 \cdot \pi^{5} \cdot \mathrm{N}_{A} \cdot n^{4}}\right) \quad\left(\text { in } \AA^{6}\right)
$$

where $\kappa^{2}$ is the orientation factor in resonance energy transfer, $Q_{D}$ is the quantum yield of the donor in the absence of acceptor, $N_{A}$ is Avogadro's number, $n$ is the refractive index of the medium, and $J(\lambda)$ is the overlap integral. To calculate this equation, $\kappa^{2}$ is designated as $2 / 3, Q_{D}$ as $0.63, \mathrm{n}$ as 1.4 , and $N_{A}$ as $6.02214076 \times 10^{23}$. The $J(\lambda)$ is calculated by (34):

$$
J(\lambda)=\frac{\int_{0}^{\infty} F_{D}(\lambda) \varepsilon_{A}(\lambda) \lambda^{4} d \lambda}{\int_{0}^{\infty} F_{D}(\lambda) d \lambda}
$$

where $F_{D}$ is the emission spectrum of the donor, $\varepsilon_{A}(\lambda)$ is the molar extinction coefficient of the acceptor at $\lambda$, which is $50000 \mathrm{~cm}^{-1} \mathrm{M}^{-1}$ for SYTO 9 . 


\section{Preparation of E. coli cells expressing PhoP-A182CouA and C. elegans DA597 for fluorescent microscopic measurement of FRET}

C. elegans phm-2(-) mutant strain DA597, which lost the grinder function, was obtained from the Caenorhabditis Genetics Center (CGC), which is supported by the National Institutes of Health - Office of Research Infrastructure Programs (P40 OD010440). E. coli BL21 cells expressing PhoP-A182CouA (AY3706) was cultured in LB medium supplemented with kanamycin $(20 \mu \mathrm{g} / \mathrm{ml})$ and chloramphenicol $(25 \mu \mathrm{g} / \mathrm{ml})$ at $37^{\circ} \mathrm{C}$ for $5 \mathrm{hrs}$ in the presence of $0.5 \mathrm{mM} \mathrm{IPTG}, 0.4 \%$ arabinose and $1 \mathrm{mM}$ CouA. Cells were collected and washed with $\mathrm{M} 9$ buffer $\left(0.3 \% \mathrm{KH}_{2} \mathrm{PO}_{4}, 0.6 \% \mathrm{Na}_{2} \mathrm{HPO}_{4}, 0.5 \% \mathrm{NaCl}, 1 \mathrm{mM} \mathrm{MgSO}\right)_{4}$. $5 \mu \mathrm{l}$ of $50 \mu \mathrm{M}$ SYTO 9 was added in $1 \mathrm{ml}$ cell suspension (final concentration $0.25 \mu \mathrm{M}$ ), which was then incubated for 15 min in the dark to enable the entry of SYTO 9 into E. coli cells. The suspension was washed with $1 \mathrm{ml} \mathrm{M9}$ buffer for three times and finally resuspended in $100 \mu \mathrm{l}$ of M9 buffer and was then placed in the center of a $60 \mathrm{~mm}$ NGM agar plate $(0.25 \%$ peptone, $0.3 \% \mathrm{NaCl}, 1.7 \%$ Bacto-agar, $1 \mathrm{mM}$ $\mathrm{CaCl}_{2}, 1 \mathrm{mM} \mathrm{MgSO}_{4}, 5 \mathrm{mg}$ cholesterol, $25 \mathrm{mM}$ phosphate buffer) in a circle (20 mm diameter) as food for the C. elegans DA597 strain. This plate is termed as AY3706-NGM plate. The eggs of DA597 were then seeded onto NGM agar plate containing E. coli OP50 (OP50-NGM) and fed for $48 \mathrm{hrs}$ at $20^{\circ} \mathrm{C}$. Ten L4 stage larva grown on the OP50-NGM plate were then transferred to the AY3706-NGM plate and fed with the AY3706 bacteria for $2 \mathrm{hrs}$ at $20^{\circ} \mathrm{C}$ before being subjected to fluorescent microscopy imaging.

\section{FRET recording using confocal fluorescent microscope}

The larva grown on the AY3706-NGM plate described above following $2 \mathrm{hr}$-incubation were placed onto an agarose pad containing 3\% agarose and 4\% 2,3-butanedione monoxime on a microscope slide. Fluorescence signal emitted from the larva was recorded using Zeiss LSM 710 confocal microscope 
using $40 \times$ oil immersion objective lens. The sample was excited at $405 \mathrm{~nm}$ and the emission fluorescence of CouA was recorded from $420 \mathrm{~nm}$ to $480 \mathrm{~nm}$. To record the emission fluorescence of SYTO 9, the sample was excited at $488 \mathrm{~nm}$ and emission fluorescence was recorded from $490 \mathrm{~nm}$ to $600 \mathrm{~nm}$. To record the fluorescence effected by FRET, the sample was excited at $405 \mathrm{~nm}$ by laser and emission fluorescence was recorded from $490 \mathrm{~nm}$ to $600 \mathrm{~nm}$.

\section{Results}

\section{CouA is successfully incorporated into a canonical TF protein CueR at a defined site}

To establish an intermolecular FRET-based transcription factor (TF)-promoter binding assay based on intermolecular FRET, we first explored the site-specific incorporation of CouA into the DNA binding domain of a canonical TF protein CueR which displays intricate interactions with its targeting promoters during the switch from a transcription repressor to an activator in response to the inducing signal. CueR is a copper $(\mathrm{Cu})$ and silver $(\mathrm{Ag})$ metalloregulatory MerR family protein that senses $\mathrm{Cu}(\mathrm{I})$ stress and activates the expression of two target genes, copA and cueO, which encodes the ATPase copper exporter CopA and copper oxidase CueO, respectively (36-38) (Fig. 1A). The mechanism of transcription regulation by CueR has been elucidated by both crystallography in which CueR is bound with a 23-bp promoter DNA (39) and by cryo-EM in which CueR, RNAP and a 58-bp promoter DNA forms a complex (40). These structural studies have suggested that CueR binds to target promoters and activates gene transcription by allosteric DNA distortion. Since CouA contains an aromatic sidechain, we first selected aromatic amino acid residues located at the relatively unstructured loop regions in the DNA binding domain (DBD) of CueR as the potential sites for CouA incorporation. The 
DBD of CueR is composed of four $\alpha$-helixes and is connected to a two-turn C-terminal $\alpha$-helix by a hinge loop and a long dimerization helix (39). It was shown that CueR binds to its target promoter as a repressor in the absence of the inducing signal $\mathrm{Cu}(39)$. Upon being bound by $\mathrm{Cu}(\mathrm{I})$, CueR undergoes a conformational change and is switched to a transcription activator, resulting in a twist of the bound DNA by tightly clamping the $\alpha 2$ and a loop wing of the DBDs, i.e., R18, 31, and 37, into DNA major grooves (Fig. 1A) (39). Based on this structural information, we chose F58 which is located at the loop region between the helix $\alpha 3$ and helix $\alpha 4$ for CouA incorporation (Fig. 1A). The calculated distance between the selected site to the two closest DNA minor grooves which should be bound by the SYTO 9 dye is $\sim 22 \AA$ and $45 \AA$, respectively. These distances are within the calculated distance range (25-75 $\AA$ ) for FRET occurrence based on the theoretical Förster radius of the CouA-SYTO 9 pair (52.5 $\AA$ ) (Fig. S1).

The genetic code encoding F58 in CueR was mutated to the amber codon TAG. In the presence of the previously optimized orthogonal tRNA/tRNA acetyltransferase MjtRNA-MjTyrRS (27) and the supplement of $1 \mathrm{mM}$ CouA (Fig. S2A), a protein band (16.2 kDa) corresponding to CueR-F58CouA-His6 was detected by fluorescent SDS-PAGE (Fig. S2B). The protein was subsequently purified and was subjected to LC-MS/MS analysis. Site-specific incorporation of CouA in CueR by replacing F58 was verified by the expected mass of y26 and b4-b15 peptides with a $174.15 \mathrm{Da}$ addition relative to the corresponding peptides derived from the WT CueR (Fig. S2C).

FRET effect between CueR-F58CouA and SYTO 9-labeled $P_{\text {copA }}$ reliably reports the CueR-PcopA binding

We next examined the occurrence of FRET and its degree effected by the binding of purified CueRF58CouA with the 200-bp DNA fragment of $\mathrm{P}_{\text {copA }}$ stained with SYTO 9 in vitro. Emission spectra of the 
bioRxiv preprint doi: https://doi.org/10.1101/2022.01 14.476424 this version posted January 15,2022 . The copyright holder for this preprint (which was not certified by peer review) is the author/funder, who has granted bioRxiv a license to display the preprint in perpetuity. It is made available under aCC-BY-NC-ND 4.0 International license.

CueR-F58CouA protein, CueR-F58CouA with the $\mathrm{P}_{\text {copA }}$ DNA fragment, and CueR-F58CouA with the free SYTO 9 were firstly recorded. Comparing with the spectra of CueR-F58CouA alone (red dash line, Fig. 1B) and CueR-F58CouA mixed with varying amounts of $P_{c o p A}$ (dash lines, Fig. 1B) which exhibit the characteristic bright fluorescence of CouA peaked at $450 \mathrm{~nm}$, addition of free SYTO 9 caused a slight decrease of the overall fluorescence intensity (red solid line, Fig. 1B), which was found to be saturated when SYTO 9 concentration is above $5 \mu \mathrm{M}$ (Fig. S3A). Since the decrease of fluorescence intensity at $450 \mathrm{~nm}$ in the mixture was not accompanied by an increase of fluorescence intensity at 500 $\mathrm{nm}$, which is the desired FRET signal for the CouA-SYTO 9 pair, this background change is mostly due to a fluorescence quenching of CouA by the free SYTO 9 and is not a false positive FRET. When the protein $(10 \mu \mathrm{M})$ was mixed with varying amount of $\mathrm{P}_{\text {copA }}$ DNA fragment in the presence of SYTO 9 (7.5 $\mu \mathrm{M})$, a significant fluorescence emission peaked at $500 \mathrm{~nm}$ appeared and the intensity increased in a $\mathrm{P}_{\text {сорA }}$ concentration dependent manner (Fig. 1B \& C), indicating that a FRET effect occurred between

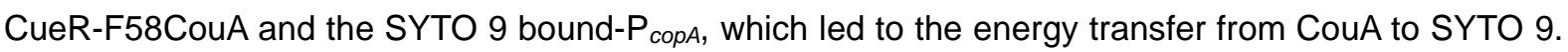
In contrast, supplying a random DNA fragment (Frag 1 ) only caused a very moderate increase at 500 $\mathrm{nm}$ and the intensity was not increased continuously with the increase of the DNA concentration (Fig. 1C), suggesting that the FRET signal observed in the mixture of CueR-F58CouA and $P_{\text {copA }}$ was effected by the specific interaction between CouA-F58CouA and the SYTO 9 bound-P $\mathrm{P}_{\text {copA. }}$. This result is consistent with the fact that CueR binds to its target promoters as a repressor in the absence of the inducing signal $\mathrm{Cu}(\mathrm{I})$. Since the background-level FRET between CueR-F58CouA with the random DNA was saturated when its concentration was above $0.3 \mu \mathrm{M}, 0.3 \mu \mathrm{M}$ DNA fragment is applied in the following assays. Next, we supplied the stimulant $\mathrm{Cu}(\mathrm{I})$ which is generated by $\mathrm{CuSO}_{4}$ in the presence of ascorbate to the assay mixture. A dose-dependent increase of the FRET signal was observed (Fig. 
1D \& E), indicating a closer proximity and improved alignment between the FRET pairs upon the binding of $\mathrm{Cu}(\mathrm{I})$ to CueR which is consistent with the clamp of the DBD into DNA grooves by the $\mathrm{Cu}(\mathrm{I})$ bound CueR activator revealed by the structural studies (39). These results demonstrated that the FRET occurrence and its degree between CouA and SYTO 9 reliably reports the intricate interaction of CueR and its targeting promoter DNA in response to the presence and strength of the inducing signal of the regulatory system.

Whole-cell FRET between CueRcouA and promotersyto 9 monitors CueR-promoter interaction in vivo

We next employed the FRET pair to monitor the TF-promoter interactions in living E. coli. To achieve this, we first optimized the condition for CouA incorporation in E. coli cells such that CouA is incorporated into CueR but the protein is not over-expressed to artificially shift or saturate the TF-promoter binding. We carried out CouA incorporation and protein expression under a mild condition (0.5 mM IPTG, 0.4\% arabinose, $1 \mathrm{mM}$ CouA for $4 \mathrm{hrs}$ at $37^{\circ} \mathrm{C}$ ) compared to that for over-expression and purification of CueRF58CouA. The expression level of CueR-F58CouA protein in the cell cultured under this condition was estimated to be $\sim 113 \mu \mathrm{g} / \mathrm{ml}$ by comparing with a series of purified CueR-F58CouA protein with known concentrations (Fig. S4A) which is less than $1 / 2000$ of total proteins in E. coli grown in LB medium at stationary stage (200-320 mg/ml) (41). This expression level affords a fluorescence intensity reading in the range of 80-120 a.u. when 10 O.D. cell suspension was subjected to fluorescence recording. Fluorescent SDS-PAGE (Fig. S2B) and fluorescent microscopy (Fig. S5A) confirmed the expression of CueR-F58CouA and the bright fluorescence of the resulting cell suspension. To determine the concentration of SYTO 9 to be applied in the whole-cell FRET assay, we first examined the background 
bioRxiv preprint doi: https://doi.org/10.1101/2022.01 14.476424 this version posted January 15,2022 . The copyright holder for this preprint (which was not certified by peer review) is the author/funder, who has granted bioRxiv a license to display the preprint in perpetuity. It is made available under aCC-BY-NC-ND 4.0 International license.

fluorescence intensity of the E. coli BL21 cell suspension host stained with a series concentrations of SYTO 9. A concentration dependent increase of the fluorescence intensity at $500 \mathrm{~nm}$ was observed in the range of 0-20 a.u. (Fig. S3B). The same SYTO 9 concentration $(7.5 \mu \mathrm{M})$ as applied in the in vitro assay was selected which is also consistent with the concentration suggested by McGoverin et al. (42) for general application of SYTO 9 to several common bacteria. Staining of the cell suspension with this concentration of SYTO 9 yielded the desired bright green fluorescence (Fig. S5A). These results confirmed the applicability of the two fluorophores in live cells.

A whole-cell FRET measurement to monitor in vivo TF-promoter binding was subsequently established. $0.1 \mathrm{mM} \mathrm{CuSO}_{4}$ was added in the cell culture during CouA incorporation and CueR-F58CouA expression to activate CueR-mediated transcription regulation. Following incubation with SYTO 9 for 15 min in the dark, the whole-cell suspension was directly subjected to emission fluorescence spectrum recording (Fig. 2A). Comparing with the spectrum without the Cu stress (cyan line, Fig. 2B) which exhibited a background level FRET (50.8\%) (Fig. 2F), an obvious FRET enhancement with a quantified FRET effect of $61.7 \%$ was observed in the cell treated with $0.1 \mathrm{mM} \mathrm{Cu}$ (purple line, Fig. 2B), suggesting that the CouA-SYTO 9 FRET pair is applicable to report the binding of CueR with its promoter in live E. coli cells in response to the Cu stress. To confirm that the observed FRET effect and its enhancement was elicited by the specific binding of CueR with its target promoters $\left(\mathrm{P}_{\text {сорA }}\right.$ and $\left.\mathrm{P}_{\text {cueo }}\right)$ in $E$. coli cells, we mutated the key arginine residues R18 and R37 (37) located at the loop wing of the promoter binding domain of CueR which are essential for DNA clamping, and conducted the assays employing E. coli cells expressing CueR-F58CouA-R18A and CueR-F58CouA-R37A, respectively. No FRET enhancement was observed when cells expressing either of the mutant proteins were treated by Cu compared to that without Cu treatment (Fig. 2C-D). Quantitation of the degree of FRET confirmed the insignificant FRET 
bioRxiv preprint doi: https://doi.org/10.1101/2022.01 14.476424 this version posted January 15,2022 The copyright holder for this preprint (which was not certified by peer review) is the author/funder, who has granted bioRxiv a license to display the preprint in perpetuity. It is made available under aCC-BY-NC-ND 4.0 International license.

changes for CueR-F58CouA-R18A and CueR-F58CouA-R37A as opposed to that (10.9\%) for the CueR-F58CouA (Fig. 2F). To further confirm the specificity of the FRET signals observed, we also conducted the assay in a mutant strain in which the two targeting promoters of CueR, $\mathrm{P}_{\text {copA }}$ and $\mathrm{P}_{\text {cueo, }}$ were deleted from the $E$. coli BL21 genome, i.e., BL21 (DE3)- $\Delta P_{\text {copA }} \Delta P_{\text {cueo. }}$. Whole-cell FRET assay in this mutant showed that deletion of the targeting promoters completely abolished the FRET effect between CueR F58OuA $_{\text {and }}$ andomoter DNAsYTo 9 (Fig. 2E \& F). These results demonstrated the specificity and sensitivity of the intermolecular FRET-based whole-cell TF-promoter binding assay we developed. To establish the CouA incorporation locations applicable for the intermolecular FRET-based TFpromoter binding assay, we incorporated CouA into several additional locations (Fig. 3A) and constructed the following variants: CueR-T27CouA, CueR-Y39CouA, and CueR-Q74CouA, in which CouA was incorporated into the loop region between the $\alpha 2$ and $\alpha 3$ in the DBD (T27CouA and Y39CouA) and the loop region between the $\alpha 4$ in the DBD and the $\alpha 5$ dimerization helix (Q74CouA). The calculated distances between these sites and the closest central minor grooves which should be bound by SYTO 9 are $26 \AA, 30 \AA$, and $36 \AA$, respectively. Whole-cell assay showed that an enhancement of FRET upon Cu treatment was also observed in cells expressing CueR-T27CouA (Fig. 3B \& E) and CueR-Y39CouA (Fig. 3C \& E), but not in cells expressing CueR-Q74CouA (Fig. 3D \& E), suggesting that the donor fluorophore (CouA) can be incorporated into multiple locations in the DBD, especially the loop regions between $\alpha$ helices, but not the distal dimerization domain for the FRET-based assay. Notably, we also constructed a plasmid encoding the CueR-P73CouA variant, but the protein was not successfully expressed despite its close proximity to Q74. This result suggested that certain residues, such as proline, is not tolerant to replacement by CouA. 


\section{The COUA-SYTO 9 FRET pair reports the intricate CueR-promoter interaction elicited by transient} signals in living cells and novel signals that activate CueR

Next, we applied the assay to detect the inactivation of the CueR regulatory system and the activation of the system by indirect or intermediate stimulant. Zinc (Zn) was indicated to inactivate CueR indirectly through transiently elevating intracellular iron (Fe) (43). To verify this regulatory circuit, we examined FRET occurrence and its degree in E. coli cells expressing CueR-F58CouA and stained with SYTO 9 in the presence of $\mathrm{Zn}$ which should suppress the CueR-promoter interaction, and $\mathrm{Zn}$ in combination with the iron chelator 2,2'-dipyridyl (DIP) which should restore the CueR-promoter interaction. As shown in Figure 3F, while a significant FRET was observed in the presence of $\mathrm{Cu}$, addition of $\mathrm{Zn}$ abolished the FRET effect. Further supplementing DIP restored the FRET effect, confirming the regulatory circuit of Zn-Fe-CueR (43).

We also employed the FRET-based assay to explore novel signals that can activate CueR. We found that supplementing $0.02 \mathrm{mM}$ manganese also resulted in an enhancement of FRET (Fig. 3G) with a calculated FRET change of $6.3 \%($ Fig. $3 \mathrm{H})$, whereas $\mathrm{Ni}(0.02 \mathrm{mM})$ did not elicit a FRET enhancement in cells expressing CueR-F58CouA, suggesting that Mn may also serve as a signal to activate CueR. To verify this finding, we performed $\beta$-galactosidase activities assay to examine the transcription of $P_{\text {copA-lac } Z \text { and }} P_{\text {cueo-lac } Z}$ in the presence of the same concentration of these metals which do not inhibit the growth of $E$. coli cells. $\beta$-galactosidase activities assay showed that $\mathrm{Mn}$ supplement indeed activated

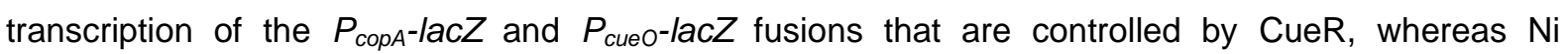
supplement did not (Fig. 3l). This result verified that the whole-cell intermolecular FRET-based assay we established is applicable to report TF-promoter interaction occurred in a complex regulatory circuit induced by indirect stimulants and can be employed to identify novel signals and conditions that 
modulate the regulatory system of interest.

\section{The intermolecular FRET-based TF-promoter binding assay monitors the signal transduction of two-component regulatory systems}

We next extended the methodology to another important type of gene regulatory system in bacteria: the two-component system (TCS). TCS is composed of a membrane-bound histidine kinase (HK) that senses the extracellular signals and a cognate response regulator (RR) that regulates gene transcription in response to signals perceived by the HK. We chose the BasSR TCS to test the application of the whole-cell intermolecular FRET-based TF-promoter binding assay. In this TCS, BasS is the $\mathrm{HK}$ which senses high iron $\left(\mathrm{Fe}^{3+}\right)$ level and phosphorylates the cognate RR BasR (Fig. 4A) (44). Phosphorylated BasR binds to the promoters of its target genes ugd, eptA, and arn operon which encodes enzymes that modify lipid A on the outer membrane of Gram-negative bacteria and activates their transcription (Fig. 4A) (45).

To monitor the activation of BasR in response to $\mathrm{Fe}^{3+}$ stress and interaction of BasR with its target promoters in vivo, we set out to incorporate CouA into the DNA binding domain of the BasR protein. The crystal structure of BasR is not available. To determine the CouA incorporation sites, we employed I-TASSER to simulate the 3D structure of BasR using the crystal structure of its homologue, Klebsiella pneumoniae PmrA (PDB ID: 4S05), as the template (46-48). Two domains were identified in the predicted structure, the receiver domain (1-121 AA) and the DNA-binding domain (125-219 AA). The DBD encompasses three $\alpha$-helices ( $\alpha 6-\alpha 8)$ and two $\beta$-sheets $(\beta 2, \beta 3)$. Four potential CouA incorporation sites were selected, G137 (located in $\beta 2$ ), E146 (located in a loop region between $\beta 2$ and a6), S167 (located in a loop region between $\alpha 6$ and $\alpha 7$ ), and D182 (located in a loop region between $\alpha 7$ and $\alpha 8$ ) (Fig. 4B). They display a calculated distance of $26 \AA, 28 \AA, 24 \AA, 22 \AA$, respectively, to the 
bioRxiv preprint doi: https://doi.org/10.1101/2022.01 14.476424 this version posted January 15,2022 . The copyright holder for this preprint (which was not certified by peer review) is the author/funder, who has granted bioRxiv a license to display the preprint in perpetuity. It is made available under aCC-BY-NC-ND 4.0 International license.

closest DNA minor grooves. Herein, we replaced the T7 promoter in pET28a to pBAD and conducted the assay in the E. coli reference strain MG1655 (35). Expression of BasR and CouA-incorporation was carried out in the presence of $0.9 \%$ arabinose. Expression of the resulting CouA-incorporated proteins (BasR-S137CouA as an example) was monitored by western-blot (Fig. S4B) and verified by fluorescent SDS-PAGE (Fig. S2B), fluorescent microscopy (Fig. S5B), and LC-MS/MS (Fig. S2D).

To monitor the activation of the BasSR in response to $\mathrm{Fe}^{3+}$ stress, E. coli MG1655 cells expressing CouA-incorporated BasR was treated with $0.5 \mathrm{mM} \mathrm{Fe}^{3+}$ in the MOPS medium for $1 \mathrm{hr}$ before being stained with SYTO 9 and subjected to emission fluorescence recording. The whole-cell suspension contained a similar ratio of the donor fusion and acceptor stain as employed in the case of CueRpromoter assay, i.e., 10 O.D cells stained with $7.5 \mu \mathrm{M}$ SYTO 9. Emission fluorescence recording showed that upon $\mathrm{Fe}^{3+}$ treatment, a statistically significant FRET enhancement relative to the non-treatment control was observed in all these cells, i.e., BasR-G137CouA, BasR-E146CouA, BasR-S167CouA, BasR-D182CouA (Fig. 4C-F). The degree of FRET enhancement was calculated to be $6.0 \%, 9.2 \%, 6.9 \%$ and 6.9\%, respectively (Fig. 4G). To verify that the FRET assay indeed reported the activation of BasR and its binding to the target promoters, we examined the phosphorylation of BasR protein under this culture and assay condition using Phos-tag SDS-PAGE. It was shown that a significant portion of BasR was phosphorylated in the presence of $0.5 \mathrm{mM} \mathrm{Fe}^{3+}$, confirming that the intermolecular FRET-based assay we developed is applicable to monitor the activation of the TCS in vivo. Furthermore, the fact that incorporation of CouA into all four selected sites resulted in the desired FRET enhancement upon stimulation and that these CouA incorporation sites were determined based on the simulated 3D structure of BasR suggested that the assay system we developed is robust to monitor the diverse signal transduction systems. 


\section{Whole-cell FRET measurement monitors the activation of PhoPQ TCS in response to different} stimulants

We next expanded the assay to the PhoPQ regulatory system which is one of the most important TCS in enterobacteria that regulates the virulence and antibiotic resistance in response to the environment of their mammalian hosts, such as low divalent cations, low $\mathrm{pH}$, antimicrobial peptides and osmotic upshift (49-55). In this TCS, PhoQ is the histidine kinase that phosphorylates and activates the response regulator PhoP upon perceiving stimulating signals. Phosphorylated and activated PhoP then binds to the target promoters to regulate gene transcription (Fig. 5A). Since the crystal structure of $E$. coli PhoP is not available, we simulated its 3D structure using the crystal structure of Mycobacterium tuberculosis PhoP-DNA complex (PDB ID: 5ED4) as the template. Two domains were shown in the simulated structure, the receiver domain (1-123 AA) and the DBD (123-223 AA). The DBD encompasses three $\alpha$ helixes ( $\alpha 6-\alpha 8)$ and two $\beta$-sheets $(\beta 2, \beta 3)$. We selected three potential sites in the DBD for CouA incorporation, S137 (located in $\beta 2$ ), D145 (located at the loop region between $\beta 2$ and $\alpha 6$ ), and A182 (located at the loop region between $\alpha 7$ and $\alpha 8$ ) (Fig. 5B). The calculated distances of D145, S137 and A182 to the closest DNA minor groove is approximately $30 \AA, 25 \AA$, and $20 \AA$, respectively. Plasmids encoding the three proteins PhoP-S137CouA, PhoP-D145CouA, and PhoP-A182CouA were successfully constructed. Fluorescent SDS-PAGE (Fig. S2B), fluorescent microscopy (Fig. S5C), and LC-MS/MS (Fig. S2E) analysis confirmed the expression of these proteins (PhoP-A182CouA as an example) and their fluorescence in E. coli cells.

We first conducted the whole-cell FRET assay to monitor the activation of the regulatory system under the condition of $\mathrm{Mg}^{2+}$ depletion. $10 \mathrm{mM} \mathrm{Mg}^{2+}$ was added in the cell suspension to ensure that PhoPQ is fully inactivated prior to applying the stimulants as reported by Bader et al. (Bader et al., 2005). 
bioRxiv preprint doi: https://doi.org/10.1101/2022 $01.14 .476424^{\circ}$ this version posted January 15,2022 The copyright holder for this preprint (which was not certified by peer review) is the author/funder, who has granted bioRxiv a license to display the preprint in perpetuity. It is made available under aCC-BY-NC-ND 4.0 International license.

Depletion of $\mathrm{Mg}^{2+}$ was initiated subsequently by supplying 20 mM EDTA following a previous description (55). An enhancement of FRET was observed in all three assay mixtures relative to the no EDTA control (Fig. 5C-E). Among them, PhoP-A182CouA displayed the greatest degree of FRET effect (7.7\%) (Fig. $5 F)$, consistent with the closest calculated distance between this site with the DNA minor groove among the three selected sites in the simulated structure.

Next, we employed the assay to detect the activation of the PhoPQ system by the cationic antimicrobial agent polymyxin B. Herein, the stimulant was applied to the cell suspension with a physiological level of $\mathrm{Mg}^{2+}(1 \mathrm{mM})$. We monitored time course of the FRET effected by PhoP-A182CouA and target promoters bound by SYTO 9 following applying varying concentrations of polymyxin B. Dose dependent FRET enhancement was observed at all three time courses: 10, 20, and 30 min (Fig 6A \& C). The FRET enhancement maintained during the entire signal recording process (30 $\mathrm{min})$, suggesting a strong and continuous activation of the PhoPQ TCS by polymyxin B. We also monitored the FRET occurrence effected by EDTA treatment in the same cell suspension, i.e., physiological level of $\mathrm{Mg}^{2+}$, and observed a similar pattern for FRET occurrence, degree, and dynamics (Fig 6 B \& D). This result suggested that PhoPQ exerts similar signal perception and regulatory response in response to these two types of stimulants and polymyxin $\mathrm{B}$ activates the PhoPQ system by competing the $\mathrm{Mg}^{2+}$ binding site in the sensor domain of PhoP as proposed by Baber et al. (Bader et al., 2005).

Whole-cell FRET-based TF-promoter binding assay enables identification of novel modulators of the PhoPQ TCS

The development of genome assembly, genetics, and high throughput gene expression analysis has allowed identification of a large number of TCS systems in bacterial genomes (56-58). However, a major bottleneck in understanding these signal transduction systems is the lack of information on the 
environmental signals and physiological conditions that trigger their activation $(59,60)$. In addition to reporting the in situ TF-promoter interaction in response to know stimulants of a signal transduction system, the FRET-based in vivo TF-promoter binding assay we developed can be employed to identify modulators of a regulatory system as demonstrated in the case of CueR above. To further prove this concept, we explored novel signals that modulate the PhoPQ TCS. Several previous DNA microarray studies indicated that a class of indole and its derivatives, such as indole-3-acetic acid (IAA) and tryptophan, and the aminoglycoside antibiotic gentamycin altered expression of PhoP in E. coli cells (61-64). It was indicated that treatment with IAA, gentamycin, and tryptophan increased the expression of PhoP, whereas indole treatment reduced its expression. To verify whether these signals indeed modulate the PhoPQ system, we treated E. coli cells expressing PhoP-A182CouA with these chemicals and monitored the FRET signal. As shown in Figure 7A \& C, treatment with $12 \mathrm{mM}$ tryptophan resulted in an enhancement of FRET (46\% to 58\%). Indole treatment, on the other hand, caused a slight reduction of FRET (Fig. 7B \& D). Growth curve analysis indicated that $2.5 \mathrm{mM}$ or above indole caused a significant reduction on the growth rate of E. coli (Fig. S6), suggesting that the reduction on FRET upon indole treatment may be due to perturbation on the growth of E. coli cells. In contrast, IAA and gentamycin treatment did not effect a FRET effect despite a broad range of concentrations and treatment time were tested (Fig. S7). These studies demonstrated that the FRET-based assay we developed is applicable to identify and verify modulators of TCSs.

FRET-based TF-promoter assay monitors the activation of the PhoPQ system in E. coli cells colonized in the $C$. elegans gut

Next, we expanded the assay system to monitor the activation of a signal transduction system and TF activities in bacteria colonized in an animal host using C. elegans as a paradigm. C. elegans is a model 
bioRxiv preprint doi: https://doi.org/10.1101/2022.01 14.476424 this version posted January 15,2022 . The copyright holder for this preprint (which was not certified by peer review) is the author/funder, who has granted bioRxiv a license to display the preprint in perpetuity. It is made available under aCC-BY-NC-ND 4.0 International license.

organism widely employed to study bacteria-host interaction due to its invariant cell lineage, simple body structure, and short life cycle $(65,66)$. The transparent body of the $C$. elegans is particularly ideal for spectroscopic analysis. Since PhoPQ serves as the primary regulatory system during the adaptation of enterobacteria to their host environments (67-69), we tested the application of the FRET-based assay to report the PhoP-promoters interaction in E. coli colonized in the C. elegans gut. We fed the C. elegans L4 stage larva with E. coli BL21 cells expressing PhoP-A182CouA (AY3706) and stained with SYTO 9 (Fig. 8A). C. elegans phm-2(-) mutant animals (DA597) were used in the experiment because they have a dysfunctional grinder (70), allowing the observation of intact E. coli in C. elegans gut. C. elegans fed with the E. coli OP50 served as a control (Fig. 8B). The expected blue fluorescence (420 to $480 \mathrm{~nm}$ ) (Fig. 8C, upper left panel) and green fluorescence (490 to 600nm) (Fig. 8C, upper right panel) which corresponds to the emission of CouA and SYTO 9, respectively, was observed in the C. elegans intestinal tract when the animals were excited at $405 \mathrm{~nm}$ and $488 \mathrm{~nm}$, respectively. Particularly, the fluorescence in the gut was shown as small puncta rather than being diffused, indicating the presence of intact $E$. coli cells emitting fluorescence of PhoP-A182CouA and SYTO 9-bound with DNA in the C. elegans gut.

To examine whether PhoPQ system is activated to bind its target promoters and regulate gene expression in the $C$. elegans gut, we excited the $C$. elegans at $405 \mathrm{~nm}$ and recorded the green fluorescence emitted by SYTO 9-bound with DNA in the C. elegans intestinal lumen (490 to $600 \mathrm{~nm}$ ) (Fig. 8C, lower left panel), i.e., FRET effect. FRET signals were recorded in several focal points in the gut lumen, indicating the binding of PhoP-A182CouA with SYTO 9 stained targeting promoters in these E. coli cells (Fig. 8C, lower left panel). Colocalization of the signals corresponding to the emission fluorescence of CouA and SYTO 9 with that of FRET further confirmed this result (Fig. 8D). Hence, the 
method we developed is applicable to examine activities of transcription factors at the bacteria-host interface.

\section{Discussion}

In recent decades, genetic codon expansion technique, which enables site-specific incorporation of genetically encoded unnatural amino acids (UAA) into proteins, has revolutionized our ability to investigate the functions of proteins and their dynamics in living systems (71-74). However, the technique has not been leveraged to study transcription regulation during the stress adaptation in bacteria which is essential to bacterial survival and infection. In this study, we encoded a bright fluorescent unnatural amino acid (FUAA) CouA site-specifically into the DNA-binding domain of bacterial transcription regulator proteins and monitored the TF-promoter interaction in response to various stimulants and stresses based on the intermolecular FRET between the FUAA and the live cell DNA stain SYTO 9. As FRET represents almost the most accessible, sensitive, and super-resolved measurement for macromolecule associations, the assay system provides a powerful tool to monitor the adaptive gene regulation in living bacteria. We showed that the intermolecular FRET-based assay is capable of monitoring the binding of TF with its target promoters and activation of the corresponding regulatory systems in diverse signal transduction processes with specificity and sensitivity. Furthermore, the assay system is applicable to screen modulators of the regulatory systems of interests and report the activities of transcription factors in bacteria colonized in the $C$. elegans host. Hence, it provides a robust TF-promoter binding assay for investigating the complex and dynamic signal transduction processes in living cells which are inaccessible by other methods currently available.

A common concern about intermolecular FRET-based biosensors is the occurrence of background 
bioRxiv preprint doi: https//doi.org/10.1101/2022.01.14.476424 this version posted January 15,2022 . The copyright holder for this preprint (which was not certified by peer review) is the author/funder, who has granted bioRxiv a license to display the preprint in perpetuity. It is made available under aCC-BY-NC-ND 4.0 International license.

noise and false positives caused by over-production of the donor and acceptor fusions and crossexcitation of the acceptor by the excitation light of the donor. The problem of cross-excitation can be effectively solved by selecting a donor fluorophore with a large Stokes shift (75). The FRET donor we employed in this study, CouA, is a fluorophore with characteristic features ideal for FRET owing to its small size, high quantum field, and large Stokes shift (27). Indeed, no cross-excitation occurred in both the in vitro and in vivo FRET measurements established herein as demonstrated by a lack of fluorescence signal at $500 \mathrm{~nm}$ in the mixture of the CueR-F58CouA protein with a series concentration of SYTO 9 (Fig. S3A) and a modest increase of fluorescence intensity at $500 \mathrm{~nm}$ in the whole-cell suspension of BL21 mixed with varying amounts of SYTO 9 (Fig. S3B). A moderate condition for protein expression and CouA incorporation was applied for the whole-cell FRET-based assay. The level of CouA-incorporated TF proteins in the cell was determined to be in the range of $100 \mu \mathrm{g} / \mathrm{ml}$ which affords sufficient fluorescence for FRET measurements but retains ample sensitivity as demonstrated by the assay of three different regulatory systems CueR, BasSR, PhoPQ in response to a broad range of signals and stresses tested. SYTO 9 is a common nucleic acids stain widely applied to identify and enumerate live bacteria in a population. Conceivably, the DNA content of a cell influences and determines the amount of SYTO 9 required to sufficiently cover the targeting promoters of the TF protein of interest. However, studies from McGoverin et al. (42) showed that nucleobase length and GC content of a bacterium did not significantly affect the SYTO 9 concentration required for enumeration of bacteria. It was proposed that the saturation concentration of SYTO 9 for a specific bacterial species was largely determined by the permeability of SYTO 9 to the bacterial cells and that micromolar $(1 \mu \mathrm{M})$ SYTO 9 affords a robust signal for enumeration of common bacterial species including $E$. coli (42). In agreement with this notion, a limited extent of fluorescence intensity change was observed in the E. coli BL21 
bioRxiv preprint doi: https://doi.org/10.1101/2022.01 14.476424 this version posted January 15,2022 . The copyright holder for this preprint (which was not certified by peer review) is the author/funder, who has granted bioRxiv a license to display the preprint in perpetuity. It is made available under aCC-BY-NC-ND 4.0 International license.

whole-cell suspension when 0.5-20 $\mu \mathrm{M}$ SYTO 9 was supplied. The SYTO 9 concentration we selected $(7.5 \mu \mathrm{M})$ afforded sufficiently bright fluorescence for both fluorimeter and fluorescent microscopy analysis and retained ample sensitivity to report the FRET occurrence and its degree in response to stress signals. Hence, the intermolecular FRET-based assay we developed provides an accessible, robust, and generalizable approach to monitor TF-promoter interactions in living bacteria.

In most applications involving the site-specific incorporation of UAA for functional characterization of proteins, the 3D structure of the proteins is often known and is required. Using the CueR transcription factor as an example, we demonstrated that structure-guided determination of CouA incorporation sites facilitated the establishment of the intermolecular FRET-based TF-promoter binding assay. However, crystal structures of many important transcription regulators and those of newly annotated regulators are unknown. Using BasR and PhoP as examples, we showed that simulated structures are reliable and applicable for determining the CouA incorporation sites for the assay. In these applications, 3D structures of BasR and PhoP were simulated by I-TASSER using the crystal structure of the corresponding homologue proteins, i.e., K. pneumoniae PmrA and M. tuberculosis PhoP, respectively, as the template. Our further analysis showed that protein 3D structures predicted by the AI-based programs such as AlphaFold and tFold $(76,77)$ in the absence of an existing template are also reliable and applicable for determination of the CouA incorporation sites (Fig. S8). Our studies demonstrated that the loop regions between $\alpha$ helices or $\beta$ sheets in the DBD are optimal locations for CouA incorporation to monitor the TF-promoter interaction. However, certain amino acid residues, such as proline, is not tolerant to replacement by UAAs. Despite this, the fact that CouA can be incorporated into multiple locations in the loop regions of DBD to report the TF-promoter binding in CueR, BasR and PhoP demonstrated the robustness and accessibility of the assay system we developed. 
Two major types of signal transduction systems existed in bacteria, the cytoplasmic one-component transcription regulators which primarily sense intracellular signals and the membrane-associated twocomponent systems which primarily sense membrane, periplasmic, and extracellular signals and stimulants. We showed that supplying inducing signals or stimulants in the assay suspension expressing the CouA-incorporated RR of TCSs elicited instant FRET. However, when the whole-cell assay was employed to monitor the binding of cytoplasmic TF CueR with its target promoters, supplementing the stimulant in the assay suspension did not yield expected FRET signal even after 40 min incubation (data not shown). Instead, when the stimulants or modulators were supplemented during CouA incorporation and protein expression, distinct FRET effect (in the presence of inducing signals) or abolishment of FRET (in the presence of signals inactivating the regulator) was observed. Hence, the stimulant application step needs to be adjusted depending on the types of the regulatory systems being investigated to enable proper signal perception.

In the past decades, the development of synthetic strategies has greatly accelerated the design and preparation of new FUAAs and nucleic acid dyes (78). With the development of these agents that display better fluorescence features, environmental sensitivity, and cell compatibility, the FRET-based assay for TF-promoter binding, and to a larger extent of protein-DNA interaction, will be continuously optimized for sensitive, robust, and broad applications.

\section{Data availability}

The mass spectrometry proteomics data have been deposited to the ProteomeXchange Consortium via the PRIDE(79) partner repository with the dataset identifier PXD030973. (Username: reviewer pxd030973@ebi.ac.uk, Password: OV7ZS40g) 


\section{Funding}

This study was supported by grants from Hong Kong Government Food and Health Bureau Health and Medical Research Fund [No. 18171042 to A.Y.]; Hong Kong University Grants Council General Research Fund [17127918 to A.Y.]; HKU Seed Fund for Basic Research [201910159291 to A.Y.]; Ministry of Science and Technology [Synthetic Biology Special Project of National Key R\&D Program, 2019YFA0906000 to H. Z].

\section{Acknowledgement}

The $C$. elegans strains used in this study were provided by the Caenorhabditis Genetics Center, which is funded by NIH Office of Research Infrastructure Programs (P40 OD010440). We thank to Dr. Chenghao Bi (Tianjin Institute of Industrial Biotechnology, Chinese Academy of Sciences) for the gift of the pCAGO plasmid. We thank to Proteomics and Metabolomics Core, Centre for PanorOmic Sciences in HKU for their help and support on proteomics analysis.

\section{Declaration of Interests}

The authors declare no competing interests. 


\section{References}

1. Fang, F.C., Frawley, E.R., Tapscott, T. and Vazquez-Torres, A. (2016) Bacterial Stress Responses during Host Infection. Cell Host Microbe, 20, 133-143.

2. $\quad$ Ron, E.Z.J.T.p. (2006) Bacterial stress response. The prokaryotes, 1012-1027.

3. Cai, Y.H. and Huang, H. (2012) Advances in the study of protein-DNA interaction. Amino Acids, 43, 1141-1146.

4. Dey, B., Thukral, S., Krishnan, S., Chakrobarty, M., Gupta, S., Manghani, C. and Rani, V. (2012) DNA-protein interactions: methods for detection and analysis. Mol Cell Biochem, 365, 279-299.

5. Vossen, K.M. and Fried, M.G.J.A.b. (1997) Sequestration StabilizeslacRepressor-DNA Complexes during Gel Electrophoresis. Anal Biochem, 245, 85-92.

6. Fried, M.G. and Liu, G. (1994) Molecular sequestration stabilizes CAP-DNA complexes during polyacrylamide gel electrophoresis. Nucleic Acids Res, 22, 5054-5059.

7. Oehler, S., Alex, R. and Barker, A.J.A.b. (1999) Is nitrocellulose filter binding really a universal assay for protein-DNA interactions? Anal Biochem, 268, 330-336.

8. Hampshire, A.J., Rusling, D.A., Broughton-Head, V.J. and Fox, K.R. (2007) Footprinting: a method for determining the sequence selectivity, affinity and kinetics of DNA-binding ligands. Methods, 42, 128-140.

9. Oda, M. and Nakamura, H. (2000) Thermodynamic and kinetic analyses for understanding sequence-specific DNA recognition. Genes Cells, 5, 319-326.

10. Pillet, F., Sanchez, A., Formosa, C., Severac, M., Trevisiol, E., Bouet, J.Y. and Anton Leberre, V. (2013) Dendrimer functionalization of gold surface improves the measurement of proteinDNA interactions by surface plasmon resonance imaging. Biosens Bioelectron, 43, 148-154.

11. Ellington, A.D. and Szostak, J.W. (1990) In vitro selection of RNA molecules that bind specific ligands. nature, 346, 818-822.

12. Myers, K.S., Park, D.M., Beauchene, N.A. and Kiley, P.J. (2015) Defining bacterial regulons using ChIP-seq. Methods, 86, 80-88.

13. Förster, T.J.A.d.p. (1948) Zwischenmolekulare energiewanderung und fluoreszenz. Annalen der physik, 437, 55-75.

14. Jares-Erijman, E.A. and Jovin, T.M. (2003) FRET imaging. Nat Biotechnol, 21, 1387-1395.

15. Roy, R., Hohng, S. and Ha, T. (2008) A practical guide to single-molecule FRET. Nat Methods, 5, 507-516.

16. Stryer, L. (1978) Fluorescence Energy-Transfer as a Spectroscopic Ruler. Annual Review of Biochemistry, 47, 819-846.

17. Periasamy, A. and Day, R. (2011) Molecular imaging: FRET microscopy and spectroscopy. Elsevier.

18. Jares-Erijman, E.A. and Jovin, T.M. (2006) Imaging molecular interactions in living cells by FRET microscopy. Curr Opin Chem Biol, 10, 409-416.

19. Sekar, R.B. and Periasamy, A. (2003) Fluorescence resonance energy transfer (FRET) microscopy imaging of live cell protein localizations. J Cell Biol, 160, 629-633.

20. Park, H., Kang, H., Ko, W., Lee, W., Jo, K. and Lee, H.S. (2015) FRET-based analysis of protein-nucleic acid interactions by genetically incorporating a fluorescent amino acid. Amino Acids, 47, 729-734. 
21. Schärfen, L. and Schlierf, M.J.M. (2019) Real-time monitoring of protein-induced DNA conformational changes using single-molecule FRET. Methods, 169, 11-20.

22. Zhang, S., Metelev, V., Tabatadze, D., Zamecnik, P.C. and Bogdanov, A. (2008) Fluorescence resonance energy transfer in near-infrared fluorescent oligonucleotide probes for detecting protein-DNA interactions. Proc Natl Acad Sci U S A 105, 4156-4161.

23. Cremazy, F.G.E., Manders, E.M.M., Bastiaens, P.I.H., Kramer, G., Hager, G.L., van Munster, E.B., Verschure, P.J., Gadella, T.W.J. and van Driel, R. (2005) Imaging in situ protein-DNA interactions in the cell nucleus using FRET-FLIM. Exp Cell Res, 309, 390-396.

24. Wiederschain, G.Y. (2011). Springer Nature BV.

25. Wang, L., Brock, A., Herberich, B. and Schultz, P.G. (2001) Expanding the genetic code of Escherichia coli. Science, 292, 498-500.

26. Lampkowski, J.S., Uthappa, D.M. and Young, D.D. (2015) Site-specific incorporation of a fluorescent terphenyl unnatural amino acid. Bioorg Med Chem Lett, 25, 5277-5280.

27. Wang, J., Xie, J. and Schultz, P.G. (2006) A genetically encoded fluorescent amino acid. J Am Chem Soc, 128, 8738-8739.

28. Summerer, D., Chen, S., Wu, N., Deiters, A., Chin, J.W. and Schultz, P.G. (2006) A genetically encoded fluorescent amino acid. Proc Natl Acad Sci U S A, 103, 9785-9789.

29. Speight, L.C., Muthusamy, A.K., Goldberg, J.M., Warner, J.B., Wissner, R.F., Willi, T.S., Woodman, B.F., Mehl, R.A. and Petersson, E.J. (2013) Efficient synthesis and in vivo incorporation of acridon-2-ylalanine, a fluorescent amino acid for lifetime and Forster resonance energy transfer/luminescence resonance energy transfer studies. J Am Chem Soc, 135, 1880618814.

30. Luo, J., Uprety, R., Naro, Y., Chou, C., Nguyen, D.P., Chin, J.W. and Deiters, A. (2014) Genetically encoded optochemical probes for simultaneous fluorescence reporting and light activation of protein function with two-photon excitation. J Am Chem Soc, 136, 15551-15558.

31. Lee, H.S., Guo, J.T., Lemke, E.A., Dimla, R.D. and Schultz, P.G. (2009) Genetic Incorporation of a Small, Environmentally Sensitive, Fluorescent Probe into Proteins in Saccharomyces cerevisiae. J Am Chem Soc, 131, 12921-+.

32. Zhao, D.D., Feng, X., Zhu, X.N., Wu, T., Zhang, X.L. and Bi, C.H. (2017) CRISPR/Cas9assisted gRNA-free one-step genome editing with no sequence limitations and improved targeting efficiency. Sci Rep-Uk, 7, 1-9.

33. Fung, D.K., Ma, Y., Xia, T., Luk, J.C. and Yan, A. (2016) Signaling by the heavy-metal sensor CusS involves rearranged helical interactions in specific transmembrane regions. Mol Microbiol, 100, 774-787.

34. Lakowicz, J.R. (2013) Principles of fluorescence spectroscopy. Springer science \& business media.

35. Blattner, F.R., Plunkett, G., 3rd, Bloch, C.A., Perna, N.T., Burland, V., Riley, M., Collado-Vides, J., Glasner, J.D., Rode, C.K., Mayhew, G.F. et al. (1997) The complete genome sequence of Escherichia coli K-12. Science, 277, 1453-1462.

36. Stoyanov, J.V., Hobman, J.L. and Brown, N.L. (2001) CueR (Ybbl) of Escherichia coli is a MerR family regulator controlling expression of the copper exporter CopA. Mol Microbiol, 39, 502-511.

37. Outten, F.W., Outten, C.E., Hale, J. and O'Halloran, T.V.J.J.o.B.C. (2000) Transcriptional Activation of an Escherichia coli Copper Efflux Regulon by the Chromosomal MerR Homologue, CueR. J Biol Chem, 275, 31024-31029. 
38. Yamamoto, K. and Ishihama, A. (2005) Transcriptional response of Escherichia coli to external copper. Mol Microbiol, 56, 215-227.

39. Philips, S.J., Canalizo-Hernandez, M., Yildirim, I., Schatz, G.C., Mondragon, A. and O'Halloran, T.V. (2015) Allosteric transcriptional regulation via changes in the overall topology of the core promoter. Science, 349, 877-881.

40. Fang, C., Philips, S.J., Wu, X., Chen, K., Shi, J., Shen, L., Xu, J., Feng, Y., O'Halloran, T.V. and Zhang, Y.J.N.C.B. (2021) CueR activates transcription through a DNA distortion mechanism. Nat Chem Biol, 17, 57-64.

41. Elowitz, M.B., Surette, M.G., Wolf, P.-E., Stock, J.B. and Leibler, S.J.J.o.b. (1999) Protein Mobility in the Cytoplasm of Escherichia coli. J Biol Chem, 181, 197-203.

42. McGoverin, C., Robertson, J., Jonmohamadi, Y., Swift, S. and Vanholsbeeck, F. (2020) Species Dependence of SYTO 9 Staining of Bacteria. Frontiers in microbiology, 11, 2149.

43. Xu, Z., Wang, P., Wang, H., Yu, Z.H., Au-Yeung, H.Y., Hirayama, T., Sun, H. and Yan, A. (2019) Zinc excess increases cellular demand for iron and decreases tolerance to copper in Escherichia coli. J Biol Chem, 294, 16978-16991.

44. Kato, A., Chen, H.D., Latifi, T. and Groisman, E.A. (2012) Reciprocal Control between a Bacterium's Regulatory System and the Modification Status of Its Lipopolysaccharide. Mol Cell, 47, 897-908.

45. Ogasawara, H., Shinohara, S., Yamamoto, K. and Ishihama, A. (2012) Novel regulation targets of the metal-response BasS-BasR two-component system of Escherichia coli. Microbiology (Reading), 158, 1482-1492.

46. Roy, A., Kucukural, A. and Zhang, Y. (2010) I-TASSER: a unified platform for automated protein structure and function prediction. Nat Protoc, 5, 725-738.

47. Yang, J., Yan, R., Roy, A., Xu, D., Poisson, J. and Zhang, Y. (2015) The I-TASSER Suite: protein structure and function prediction. Nat Methods, 12, 7-8.

48. Yang, J. and Zhang, Y. (2015) I-TASSER server: new development for protein structure and function predictions. Nucleic Acids Res, 43, W174-181.

49. Hoch, J.A. (2000) Two-component and phosphorelay signal transduction. Curr Opin Microbiol, 3, 165-170.

50. Stock, A.M., Robinson, V.L. and Goudreau, P.N. (2000) Two-component signal transduction. Annu Rev Biochem, 69, 183-215.

51. Prost, L.R., Daley, M.E., Le Sage, V., Bader, M.W., Le Moual, H., Klevit, R.E. and Miller, S.I. (2007) Activation of the bacterial sensor kinase PhoQ by acidic pH. Mol Cell, 26, 165-174.

52. Bader, M.W., Sanowar, S., Daley, M.E., Schneider, A.R., Cho, U., Xu, W., Klevit, R.E., Le Moual, H. and Miller, S.I. (2005) Recognition of antimicrobial peptides by a bacterial sensor kinase. Cell, 122, 461-472.

53. Vescovi, E.G., Ayala, Y.M., Di Cera, E. and Groisman, E.A. (1997) Characterization of the bacterial sensor protein PhoQ. Evidence for distinct binding sites for $\mathrm{Mg} 2+$ and $\mathrm{Ca} 2+$. J Biol Chem, 272, 1440-1443.

54. Yuan, J., Jin, F., Glatter, T. and Sourjik, V. (2017) Osmosensing by the bacterial PhoQ/PhoP two-component system. Proc Natl Acad Sci U S A, 114, E10792-E10798.

55. Véscovi, E.G., Soncini, F.C. and Groisman, E.A.J.C. (1996) Mg2+ as an extracellular signal: environmental regulation of Salmonella virulence. Cell, 84, 165-174. 
56. Beier, D. and Gross, R. (2006) Regulation of bacterial virulence by two-component systems. Curr Opin Microbiol, 9, 143-152.

57. Capra, E.J. and Laub, M.T. (2012) Evolution of two-component signal transduction systems. Annu Rev Microbiol, 66, 325-347.

58. Francis, V.I. and Porter, S.L. (2019) Multikinase Networks: Two-Component Signaling Networks Integrating Multiple Stimuli. Annu Rev Microbiol, 73, 199-223.

59. Martín-Mora, D., Fernández, M., Velando, F., Ortega, Á., Gavira, J.A., Matilla, M.A. and Krell, T. (2018) Functional annotation of bacterial signal transduction systems: progress and challenges. International journal of molecular sciences, 19, 3755.

60. Matilla, M.A., Velando, F., Martín-Mora, D., Monteagudo-Cascales, E. and Krell, T. (2021) A catalogue of signal molecules that interact with sensor kinases, chemoreceptors and transcriptional regulators. FEMS Microbiology Reviews.

61. Bianco, C., Imperlini, E., Calogero, R., Senatore, B., Pucci, P. and Defez, R. (2006) Indole-3acetic acid regulates the central metabolic pathways in Escherichia coli. Microbiology (Reading), 152, 2421-2431.

62. Dwyer, D.J., Belenky, P.A., Yang, J.H., MacDonald, I.C., Martell, J.D., Takahashi, N., Chan, C.T.Y., Lobritz, M.A., Braff, D., Schwarz, E.G. et al. (2014) Antibiotics induce redox-related physiological alterations as part of their lethality. Proc Natl Acad Sci U S A 111, E2100-E2109.

63. Khodursky, A.B., Peter, B.J., Cozzarelli, N.R., Botstein, D., Brown, P.O. and Yanofsky, C. (2000) DNA microarray analysis of gene expression in response to physiological and genetic changes that affect tryptophan metabolism in Escherichia coli. Proc Natl Acad Sci U S A 97, 1217012175.

64. Bansal, T., Englert, D., Lee, J., Hegde, M., Wood, T.K. and Jayaraman, A. (2007) Differential effects of epinephrine, norepinephrine, and indole on Escherichia coli O157:H7 chemotaxis, colonization, and gene expression. Infect Immun, 75, 4597-4607.

65. Tan, M.W., Mahajan-Miklos, S. and Ausubel, F.M. (1999) Killing of Caenorhabditis elegans by Pseudomonas aeruginosa used to model mammalian bacterial pathogenesis. Proc Natl Acad Sci U S A 96, 715-720.

66. Kurz, C.L. and Ewbank, J.J. (2000) Caenorhabditis elegans for the study of host-pathogen interactions. Trends Microbiol, 8, 142-144.

67. Vadyvaloo, V., Viall, A.K., Jarrett, C.O., Hinz, A.K., Sturdevant, D.E. and Joseph Hinnebusch, B. (2015) Role of the PhoP-PhoQ gene regulatory system in adaptation of Yersinia pestis to environmental stress in the flea digestive tract. Microbiology (Reading), 161, 1198-1210.

68. Rychlik, I. and Barrow, P.A. (2005) Salmonella stress management and its relevance to behaviour during intestinal colonisation and infection. FEMS Microbiol Rev, 29, 1021-1040.

69. Porcheron, G., Schouler, C. and Dozois, C.M. (2016) Survival games at the dinner table: regulation of Enterobacterial virulence through nutrient sensing and acquisition. Curr Opin Microbiol, 30, 98-106.

70. Avery, L. (1993) The genetics of feeding in Caenorhabditis elegans. Genetics, 133, 897-917.

71. Vargas-Rodriguez, O., Sevostyanova, A., Soll, D. and Crnkovic, A. (2018) Upgrading aminoacyl-tRNA synthetases for genetic code expansion. Curr Opin Chem Biol, 46, 115-122.

72. Wang, Q., Parrish, A.R. and Wang, L. (2009) Expanding the genetic code for biological studies. Chem Biol, 16, 323-336. 
73. Lv, X., Yu, Y., Zhou, M., Hu, C., Gao, F., Li, J., Liu, X., Deng, K., Zheng, P., Gong, W. et al. (2015) Ultrafast photoinduced electron transfer in green fluorescent protein bearing a genetically encoded electron acceptor. J Am Chem Soc, 137, 7270-7273.

74. Zhang, W.H., Otting, G. and Jackson, C.J. (2013) Protein engineering with unnatural amino acids. Curr Opin Struct Biol, 23, 581-587.

75. Santana-Calvo, C., Romero, F., López-González, I. and Nishigaki, T. (2018) Robust evaluation of intermolecular FRET using a large Stokes shift fluorophore as a donor. BioTechniques, $\mathbf{6 5}$, 211-218.

76. Shen, T., Wu, J.X., Lan, H.D., Zheng, L.Z., Pei, J.G., Wang, S., Liu, W. and Huang, J.Z. (2021) When homologous sequences meet structural decoys: Accurate contact prediction by tFold in CASP14-(tFold for CASP14 contact prediction). Proteins.

77. Jumper, J., Evans, R., Pritzel, A., Green, T., Figurnov, M., Ronneberger, O., Tunyasuvunakool, K., Bates, R., Zidek, A., Potapenko, A. et al. (2021) Highly accurate protein structure prediction with AlphaFold. Nature, 596, 583-589.

78. Rombouts, K., Braeckmans, K. and Remaut, K. (2016) Fluorescent Labeling of Plasmid DNA and mRNA: Gains and Losses of Current Labeling Strategies. Bioconjug Chem, 27, 280-297.

79. Perez-Riverol, Y., Bai, J., Bandla, C., García-Seisdedos, D., Hewapathirana, S., Kamatchinathan, S., Kundu, D.J., Prakash, A., Frericks-Zipper, A. and Eisenacher, M. (2022) The PRIDE database resources in 2022: a hub for mass spectrometry-based proteomics evidences. Nucleic acids research, 50, D543-D552. 
bioRxiv preprint doi: https://doi. org/10.1101/2022 01.14.476424 this version posted January 15,2022 . The copyright holder for this preprint (which was not certified by peer review) is the author/funder, who has granted bioRxiv a license to display the preprint in perpetuity. It is made available under aCC-BY-NC-ND 4.0 International license.

Figures

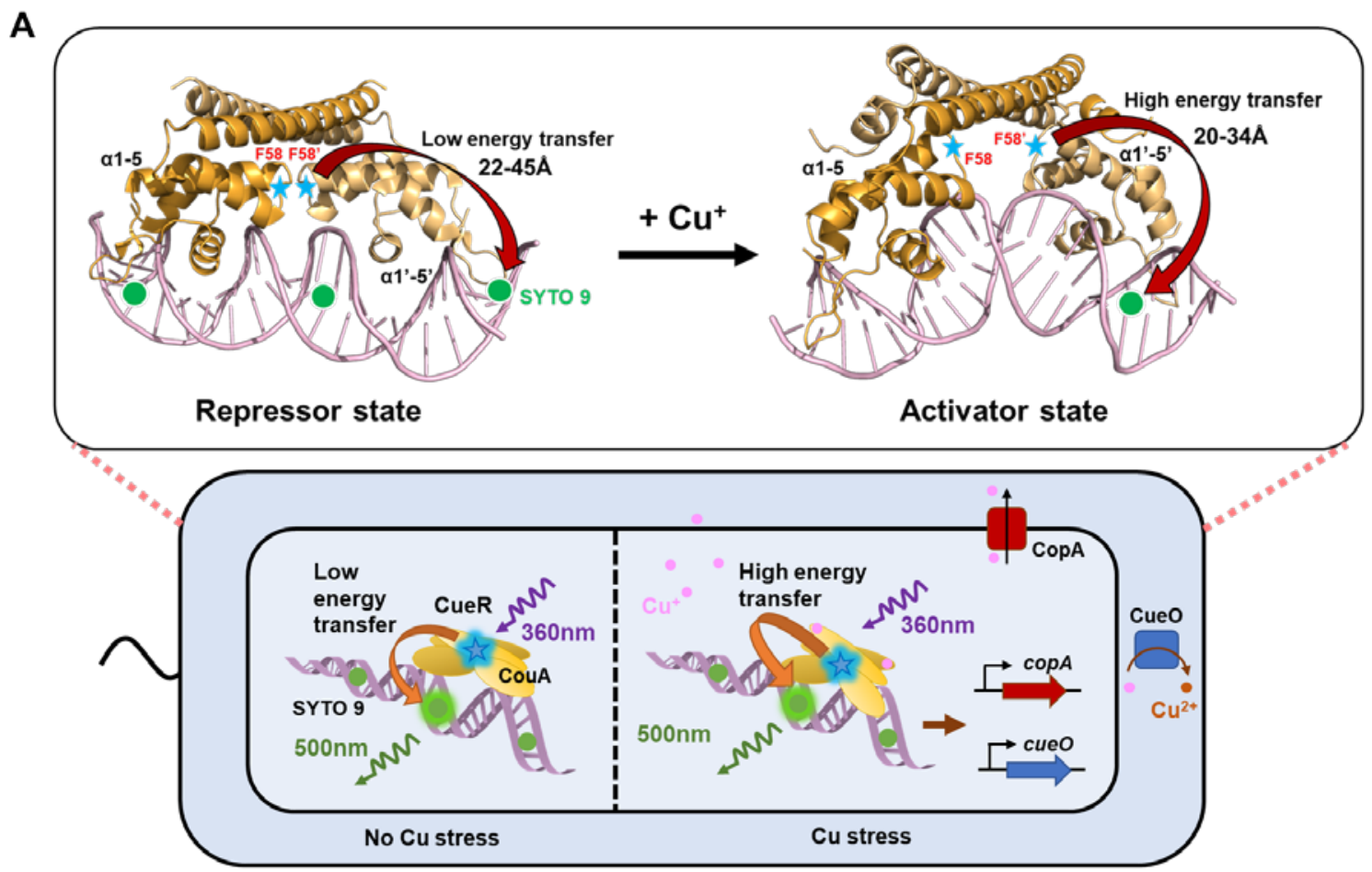

B
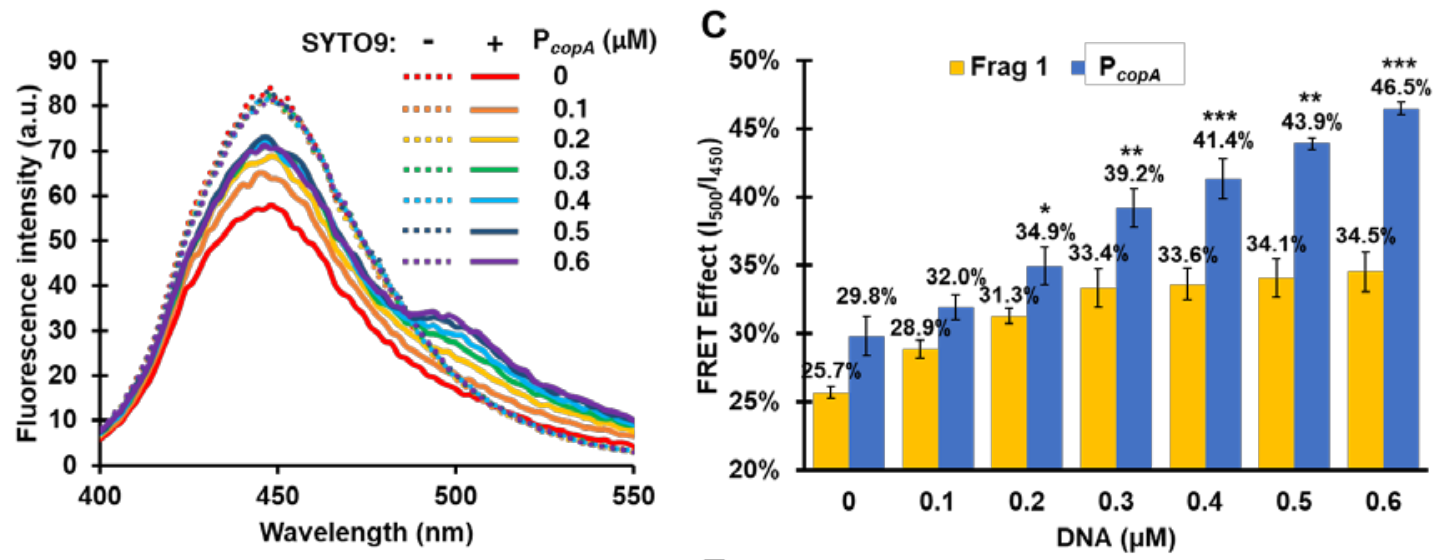

D
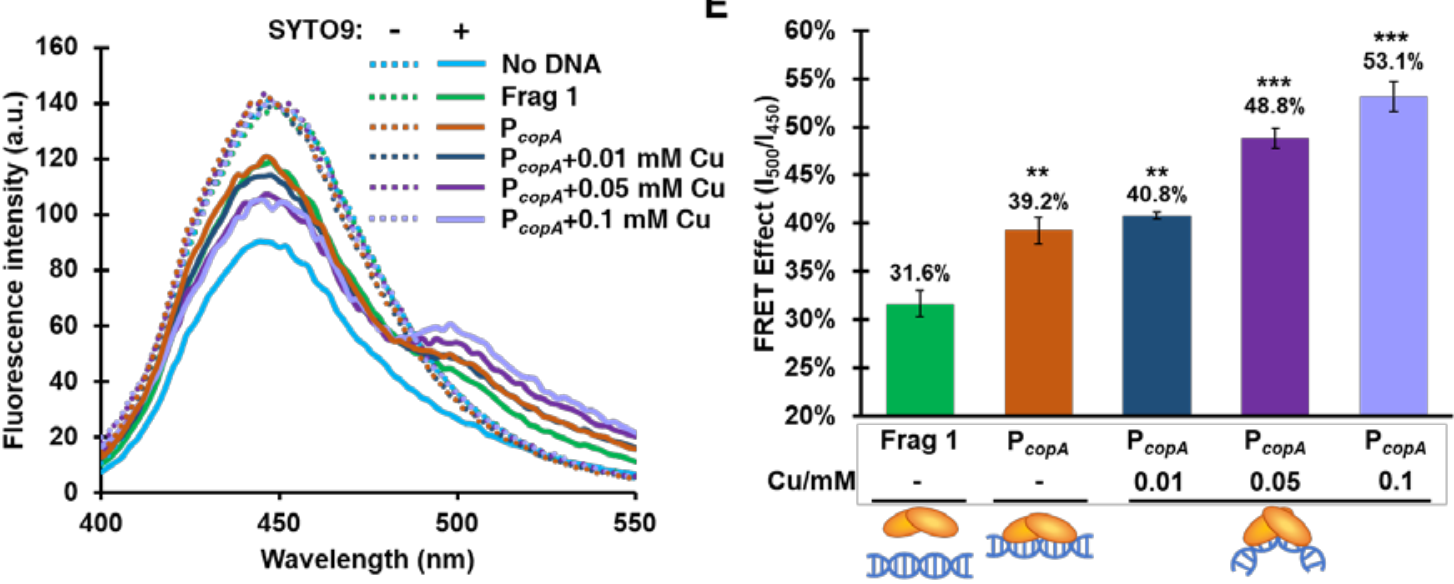
Figure 1. Schematic diagram of the intermolecular FRET-based TF-promoter binding assay and verification of the CouA-SYTO 9 FRET pair employing the activities of CueR as an example. (A) Diagram of the intermolecular FRET-based TF-promoter binding assay. Structure of the CueR-promoter DNA complex in the repressor and activator state is shown. Ribbon structure of CueR-DNA complexes were adopted from the crystal structure of E. coli CueR bound to the copA promoter DNA (PDB ID: 4WLW, 4WLS). The site for CouA incorporation, F58, was shown. Calculated distance between CouA in the F58 position and SYTO 9 bound to a proximal DNA minor groove was shown. FRET effect in the activator-promoter binding state (increase in FRET efficiency) is expected. Blue spheres, CouA (Ex: 360 nm, Em: 450 nm); Green spheres, SYTO 9 (Ex: 483 nm, Em: 503 nm). (B) Fluorescent spectra of $10 \mu \mathrm{M}$ CueR-F58CouA purified protein mixed with the $\mathrm{P}_{\text {copA }}$ DNA fragment $(0-0.6 \mu \mathrm{M})$ in the presence of SYTO $9(7.5 \mu \mathrm{M})$. (C) FRET effect (reflected by intensity ratio of $500 \mathrm{~nm}$ to $450 \mathrm{~nm}$ ) of the CouASYTO 9 pair. (D) Fluorescence spectra of purified CueR-F58CouA incubated with a random DNA fragment (Frag 1), $\mathrm{P}_{\text {сорA }}$, or $\mathrm{P}_{\text {copA }}$ with a series concentration of $\mathrm{Cu}^{+}(0-0.1 \mathrm{mM})$ in the presence or absence of SYTO 9. (E) FRET effect of the CouA-SYTO 9 pair in the assay mixtures. $P_{\text {copA, DNA }}$ fragment of promoter region of copA gene; Frag1, random DNA fragment corresponding to $+1-+142$ bp in CueR. Data are the mean of three biological repeats and are expressed as mean $\pm \mathrm{SD}$. ${ }^{*}, P<0.05$; ${ }^{\star \star}, P<0.01 ;{ }^{* \star}, P<0.001$ (based on Student's $t$ test). See also Figure S1, S2 \& S3. 
A
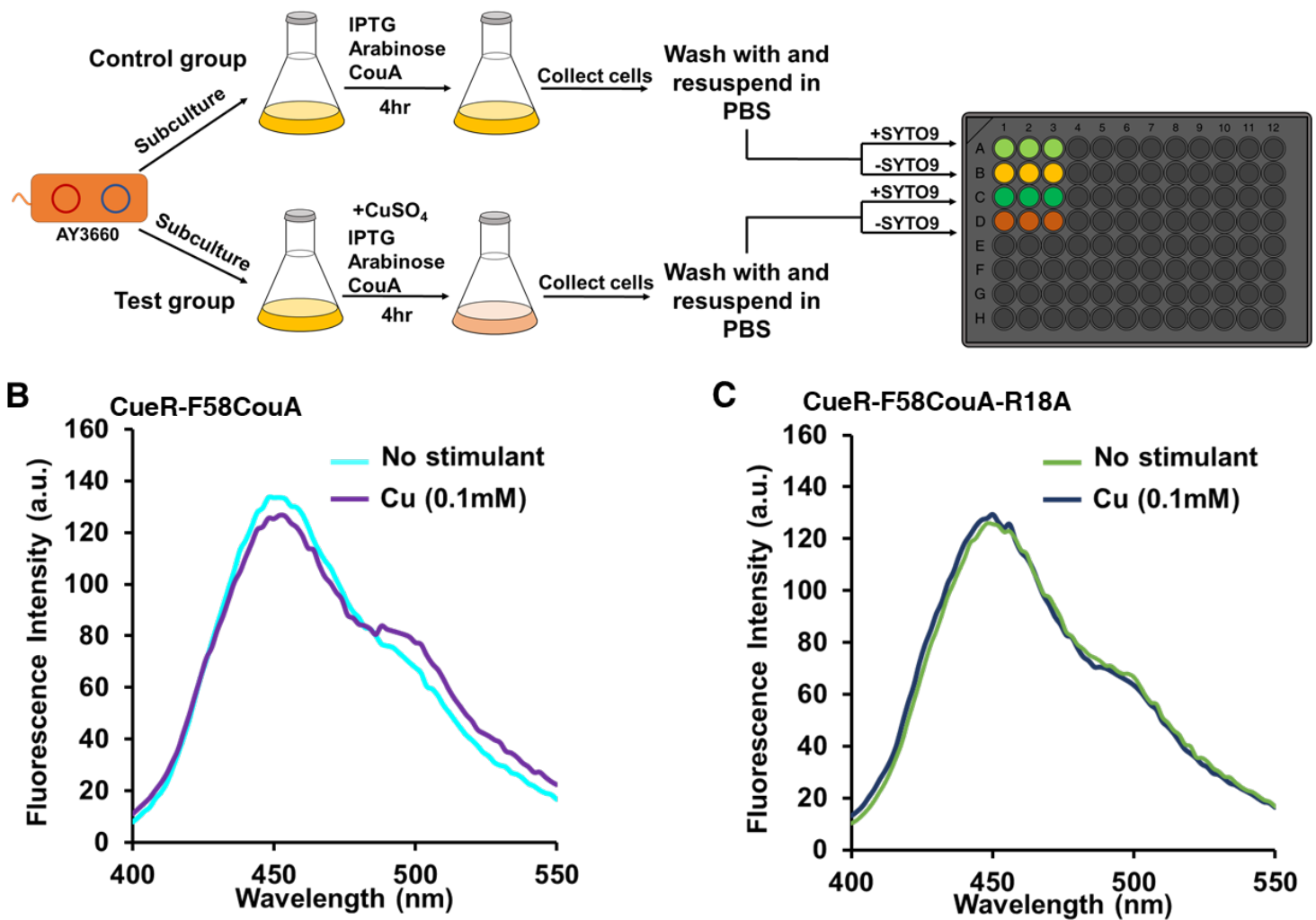

C CueR-F58CouA-R18A

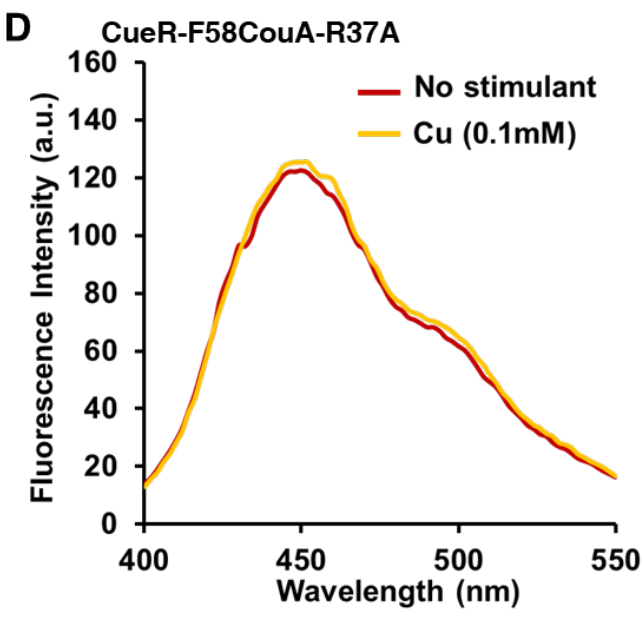

E
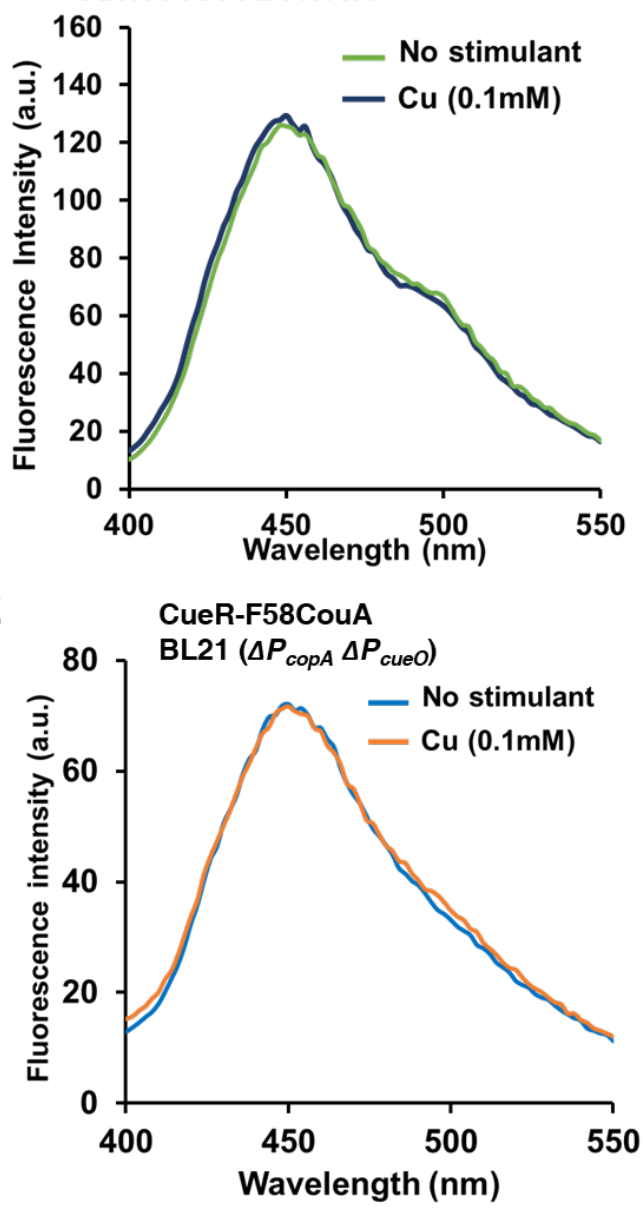

$\mathbf{F}$

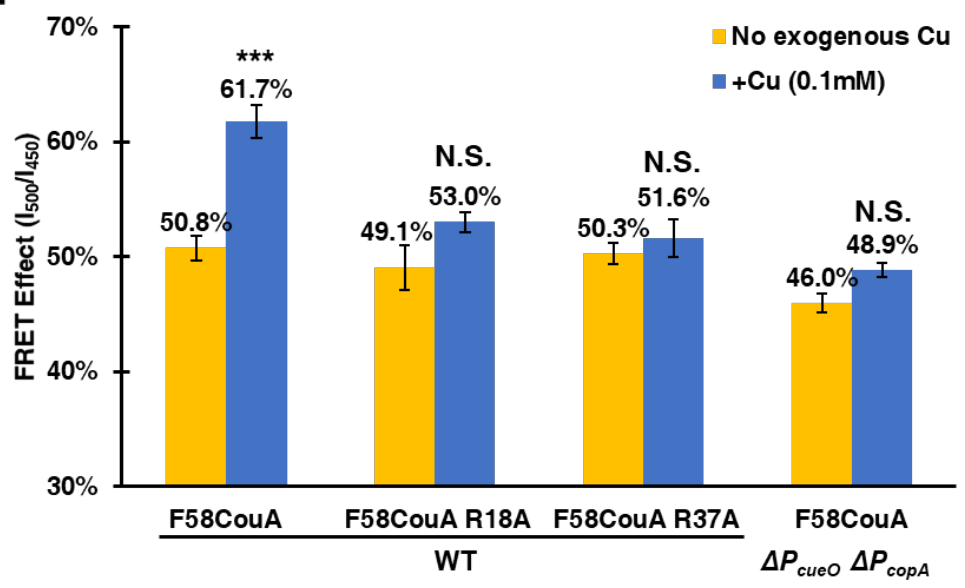


Figure 2. The intermolecular FRET-based TF-promoter binding assay detects the specific interaction of CueR with its regulated promoters in living E. coli. (A) Sample preparation workflow for the FRET-based CueR-promoter binding assay in vivo. $0.1 \mathrm{mM} \mathrm{CuSO}_{4}$ was added to the test group to activate CueR. Cell suspension was incubated in the dark for $15 \mathrm{~min}$ before being subjected to fluorescence recording. (B-D) Fluorescence spectra of BL21 (DE3) cells expressing CueR-F58CouA (AY3660) (B), or CueRF58CouA-R18A (AY3719) (C), or CueR-F58CouA-R18A (AY3720) (D), under non-inducing condition and in the presence of $0.1 \mathrm{mM} \mathrm{CuSO}_{4}$. All data are normalized against the conditions of no SYTO 9 addition. (E) Fluorescence spectrum of BL21 (DE3)- $\Delta P_{\text {copA }} \Delta P_{\text {cueo }}$ cells (AY7038) expressing CueRF58CouA under non-inducing condition (blue) and in the presence of $0.1 \mathrm{mM} \mathrm{CuSO}_{4}$ (orange). (F) FRET effect of the CouA-SYTO 9 pair in the designated assay mixtures. Data are the mean of three biological repeats and are expressed as mean \pm SD. ${ }^{*}, P<0.05 ;{ }^{*}, P<0.01 ;{ }^{* \star \star}, P<0.001$, N.S., not significant relative to the no metal treatment (based on Student's $t$ test). See also Figure S3, S4 \& S5. 
bioRxiv preprint doi: https://doi.org/10.1101/2022.01.14.476424 this version posted January 15, 2022. The copyright holder for this

A

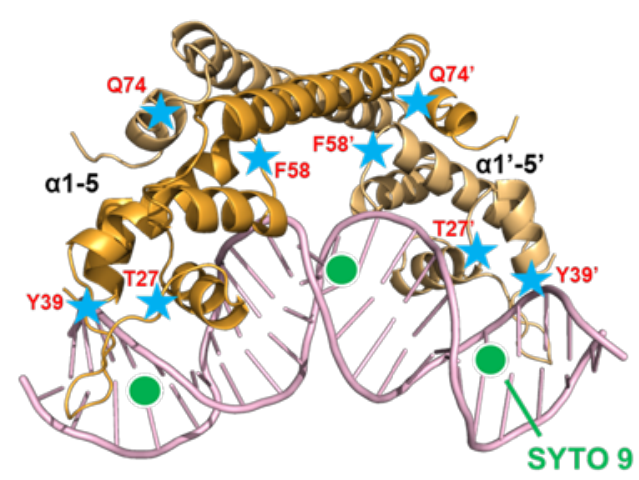

C

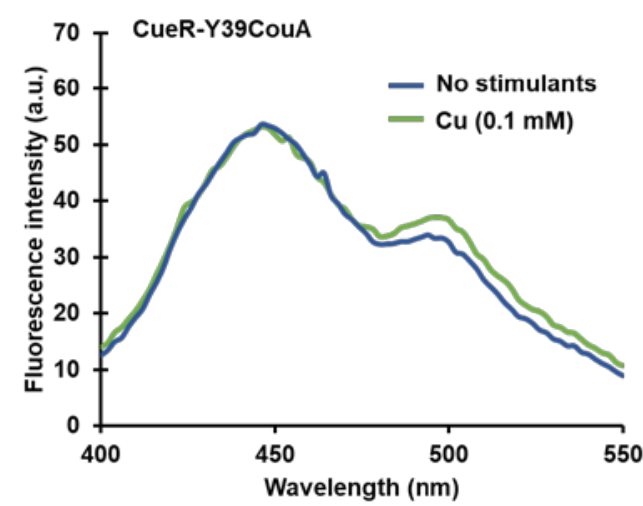

E
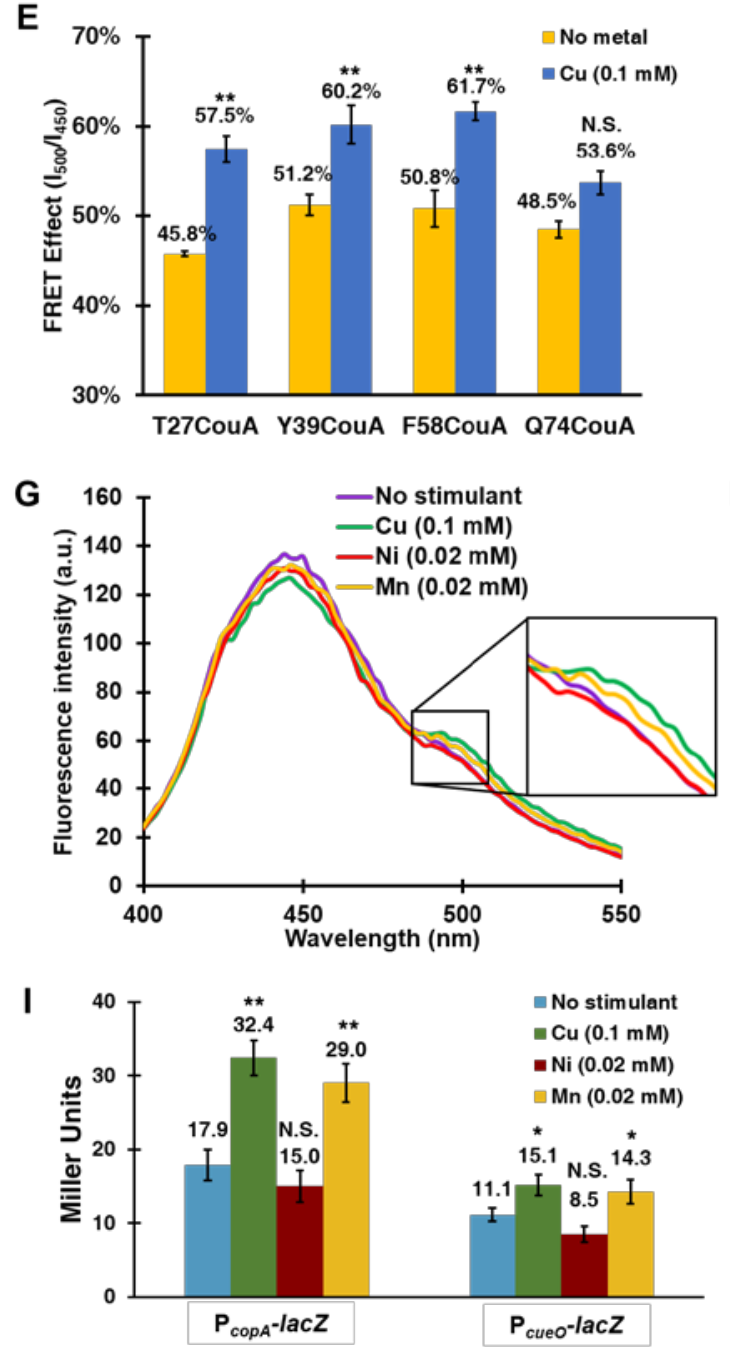
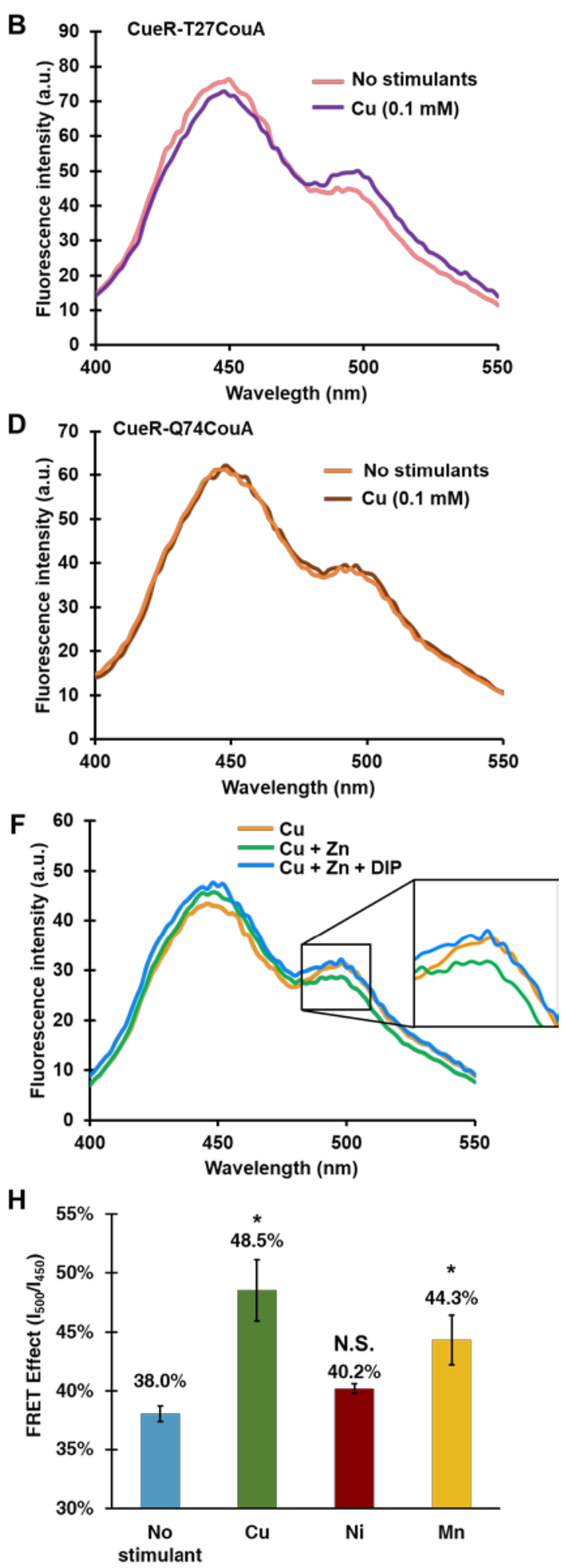
Figure 3. Whole-cell intermolecular FRET-based TF-promoter binding assay reports the intricate interactions of CueR-promoters in living cells. (A) Diagram showing the locations of CouA incorporation sites tested. CueR is shown in its active state (4WLW). The blue star represents CouA, and the green spheres represent SYTO 9. (B-D) Fluorescence spectra of BL21 (DE3) cells expressing CueRT27CouA (B), or CueR-Y39CouA (C), or CueR-Q74CouA (D) in the presence or absence of $0.1 \mathrm{mM}$ CuSO 4. (E) FRET effict of the CouA-SYTO 9 pair in the designated cell suspensions. (F-G) Fluorescence spectra of BL21 (DE3) cells expressing CueR-F58CouA in the presence of $0.1 \mathrm{mM}$ $\mathrm{CuSO}_{4}$ (orange), $0.1 \mathrm{mM} \mathrm{CuSO}_{4}$ and $0.1 \mathrm{mM} \mathrm{ZnCl}_{2}$, and $0.1 \mathrm{mM} \mathrm{CuSO}_{4}, 0.1 \mathrm{mM} \mathrm{ZnCl}_{2}$ and $0.2 \mathrm{mM}$ DIP (blue) (F), $0.1 \mathrm{mM} \mathrm{CuSO}_{4}, 0.02 \mathrm{mM} \mathrm{NiCl}_{2}$ (red), and $0.02 \mathrm{mM} \mathrm{MnCl}_{2}$ (dark green) (G). All data are normalized against the conditions without SYTO 9 addition. (H) FRET effect of the CouA-SYTO 9 pair

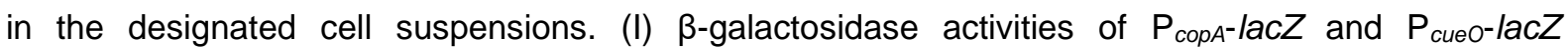
transcription fusions in the presence of $\mathrm{Cu}, \mathrm{Mn}$ and $\mathrm{Ni}$. Data are the mean of three biological repeats and are expressed as mean \pm SD. ${ }^{*}, P<0.05 ;{ }^{* \star}, P<0.01 ;{ }^{* \star *}, P<0.001$, N.S., not significant relative to no metal treatment (based on Student's $t$ test). See also Figure S8. 
A

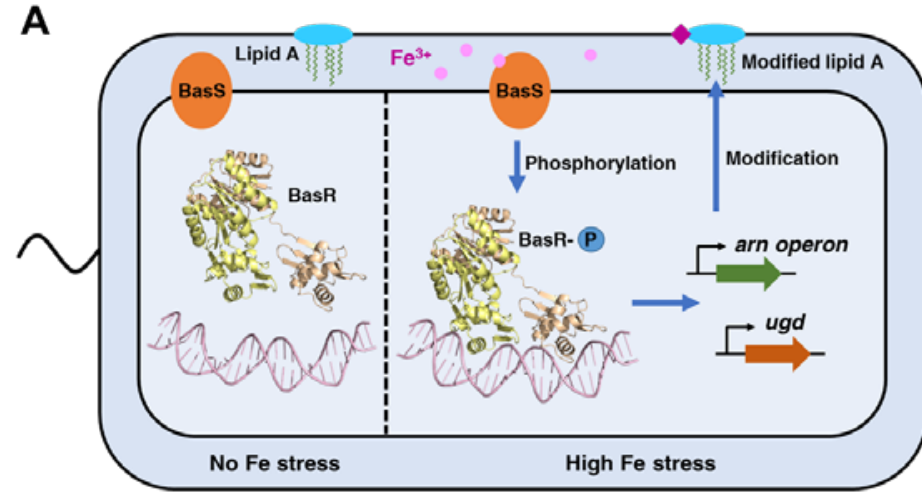

B

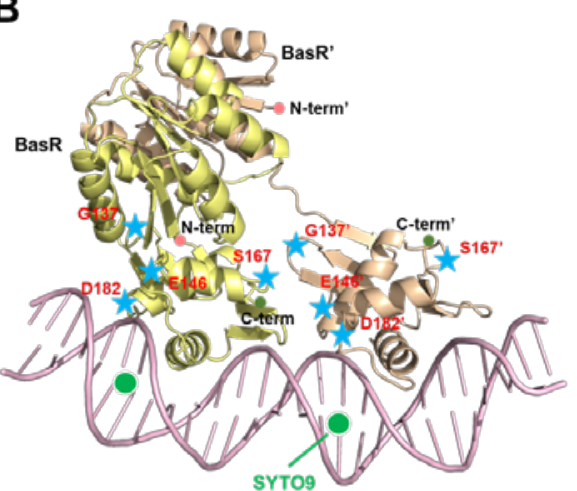

C

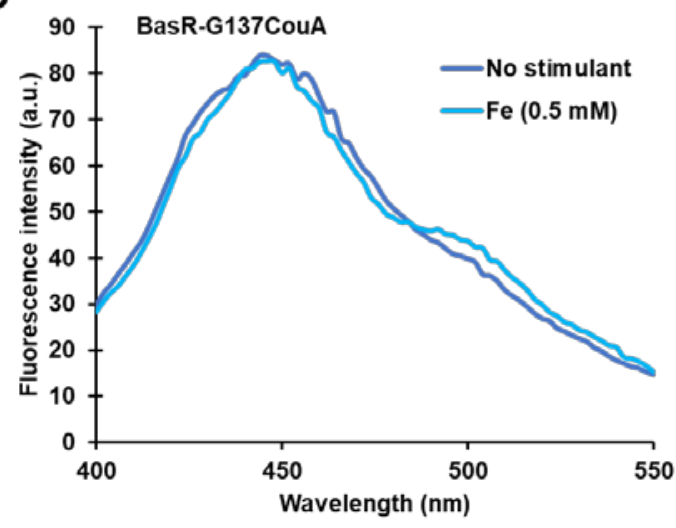

E

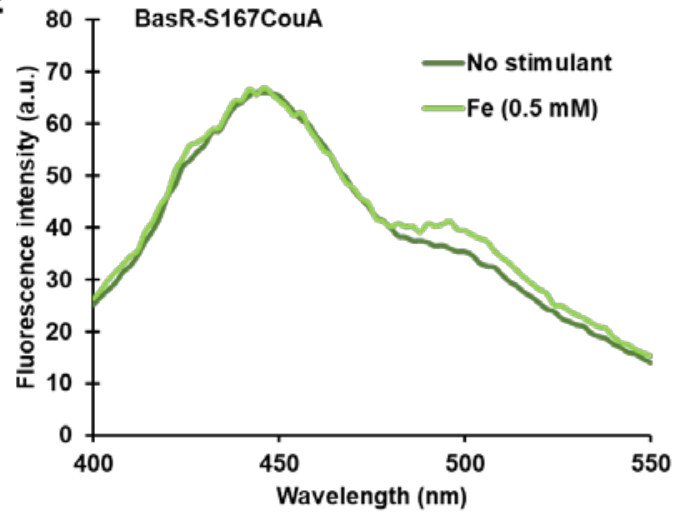

G

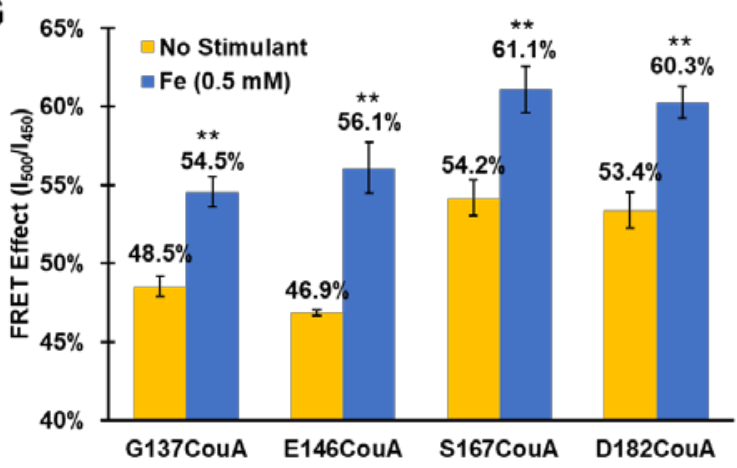

D

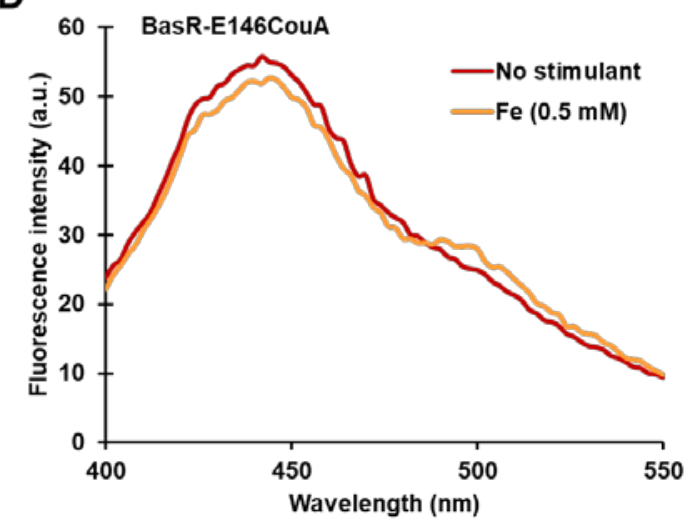

$\mathbf{F}$

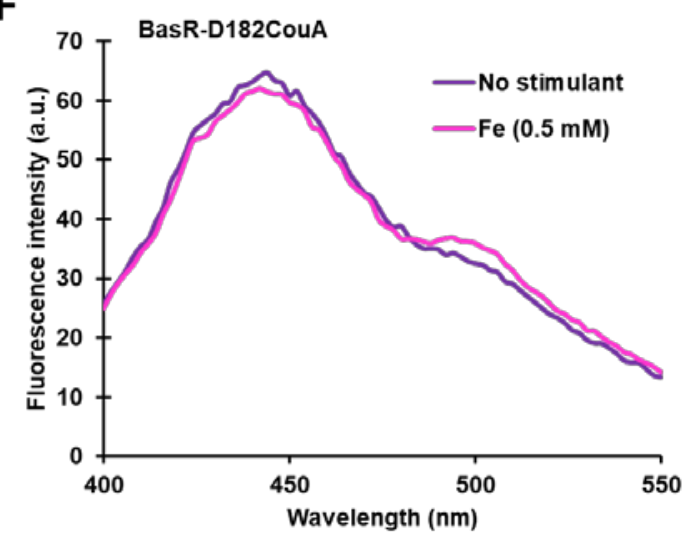

H

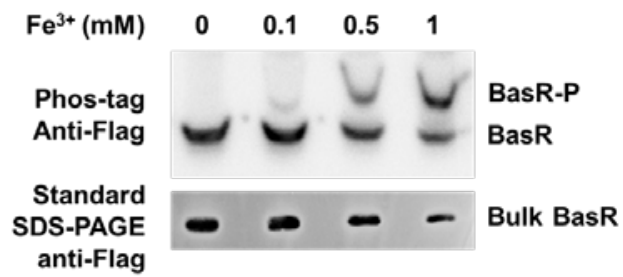


Figure 4. The intermolecular FRET-based TF-promoter binding assay system monitors activities of the two-component system BasSR in vivo. (A) Diagram showing the signal transduction of the BasSR TCS. (B) Diagram showing the locations of CouA incorporation sites in BasR being teste. BasR is shown in its active state. The blue stars represent CouA, and green spheres represent SYTO 9. Ribbon structure of BasR was simulated using the I-TASSER server. DNA fragment was adopted from Crystal structure of Klebsiella pneumoniae PmrA (PDB ID: 4S05). (C-F) Fluorescence spectra of MG1655 cells expressing BasR-G137CouA (C), BasR-E146CouA (D), BasR-S167CouA (E) and BasR-D182CouA (F) in the presence or absence of $0.5 \mathrm{mM} \mathrm{Fe}^{3+}$. (G) FRET effect of the CouA-SYTO 9 pair in the designated assay mixtures. $(\mathrm{H})$ Phosphorylation of BasR in the presence of a series of $\mathrm{FeCl}_{3}$ detected by Phos-tag SDS-PAGE. Bands corresponding to phosphorylated (BasR-P) and unphosphorylated BasR (BasR) are indicated. Data are the mean of three biological repeats and are expressed as mean $\pm \mathrm{SD}$. ${ }^{*}, P<0.05$; **, $P<0.01 ;{ }^{\star \star \star}, P<0.001$, N.S., not significant relative to no metal treatment (based on Student's $t$ test). See also Figure S2, S4, S5 \& S8. 
bioRxiv preprint doi: https://doi org/10.1101/2022 01.14.476424 - this version posted January 15, 2022. The copyright holder for this
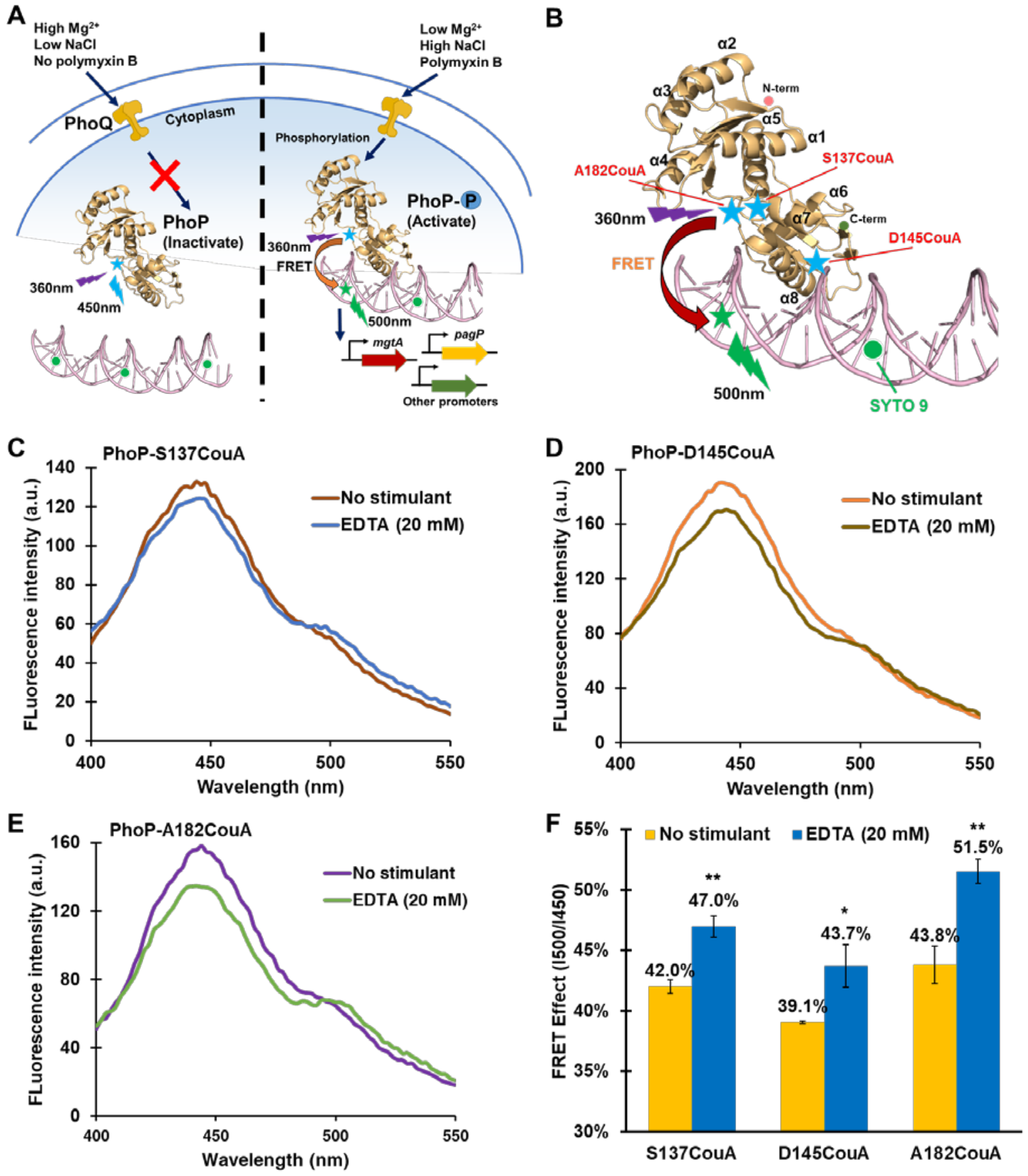
Figure 5. The intermolecular FRET-based TF-promoter binding assay monitors the activities of the PhoPQ TCS. (A) Diagram of the intermolecular FRET-based PhoP-promoter binding assay. Blue stars, CouA (Ex: 360 nm, Em: 450 nm); Green spheres, SYTO 9 (Ex: 483 nm, Em: 503 nm). (B) Diagram showing the locations of CouA incorporation sites in PhoP. PhoP is shown in its active state. Blue stars represent CouA, and green spheres represent SYTO 9. Ribbon structure of PhoP was simulated using the I-TASSER server. DNA fragment was adopted from Crystal structure of Mycobacterium tuberculosis PhoP-DNA complex (PDB ID: 5ED4). (C-E) Fluorescence spectra of BL21 (DE3) cells expressing PhoPS137CouA (C), or PhoP-D145CouA (D), or PhoP-A182CouA (E) and stained with SYTO 9 in the presence or absence of 20 mM EDTA. (F) FRET effect of the CouA-SYTO 9 pair in the corresponding assay mixtures. Data are the mean of three biological repeats and are expressed as mean \pm SD. *, $P<0.05 ;{ }^{* \star}, P<0.01 ;{ }^{* \star *}, P<0.001$, N.S., not significant relative to no EDTA treatment (based on Student's $t$ test). See also Figure S5 \& S8. 


\section{A}

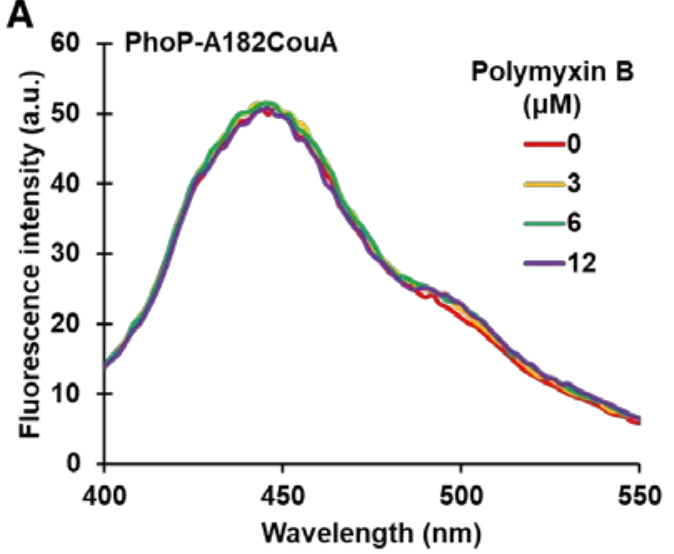

C

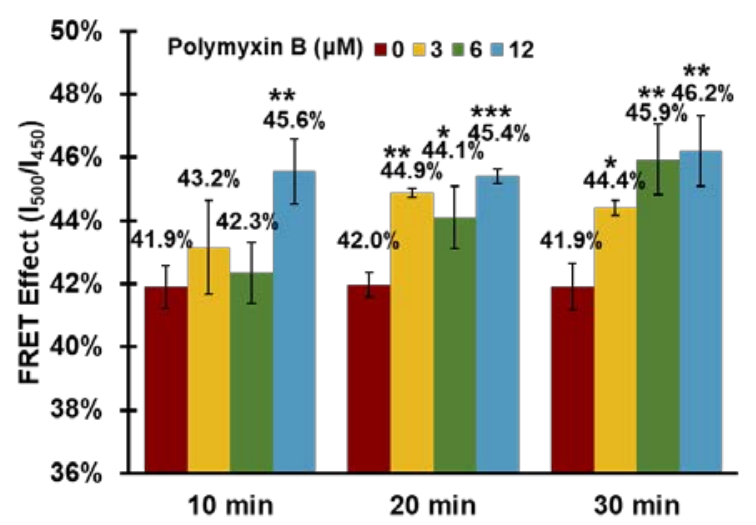

B

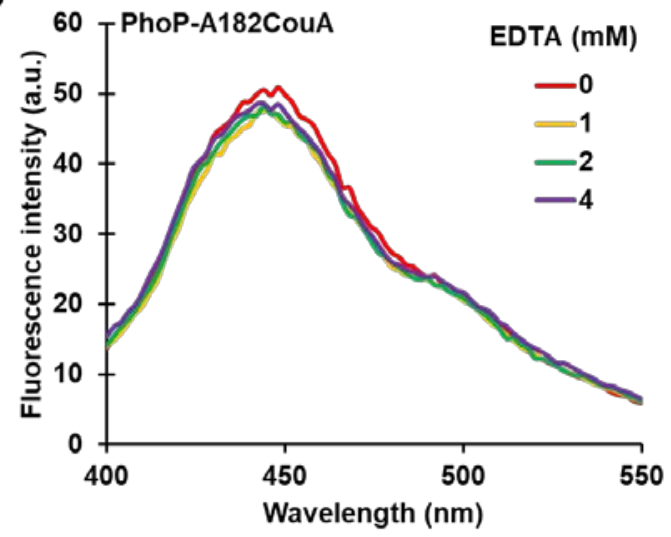

D

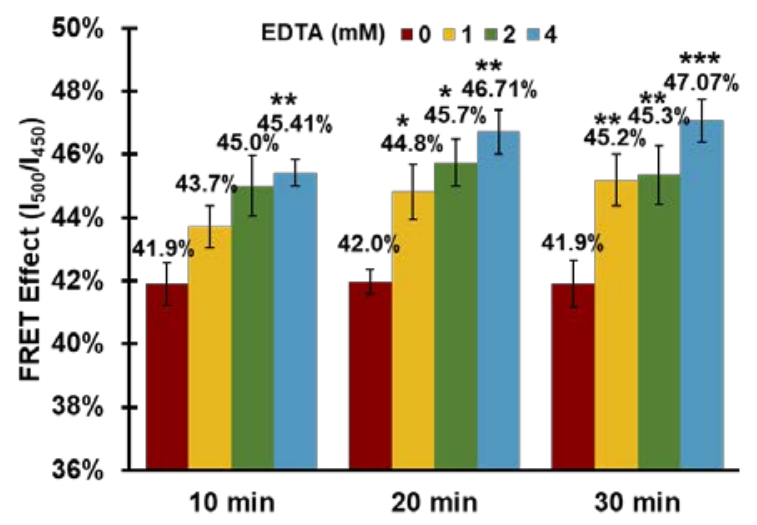

Figure 6. Comparison of PhoP activities in response to $\mathrm{Mg}^{2+}$ depletion and polymyxin $\mathrm{B}$ treatment. (A \& B) Fluorescence spectra of BL21 (DE3) cells expressing PhoP-A182CouA (AY3709) treated by polymyxin B (A), or EDTA (B). (C \& D) FRET effect of the CouA-SYTO 9 pair in the designated assay mixtures. Data are the mean of three biological repeats and are expressed as mean $\pm \mathrm{SD}$. ${ }^{*}, P<0.05$; ${ }^{* *}, P<0.01 ;{ }^{* * *}, P<0.001$ (based on Student's $t$ test). 
A

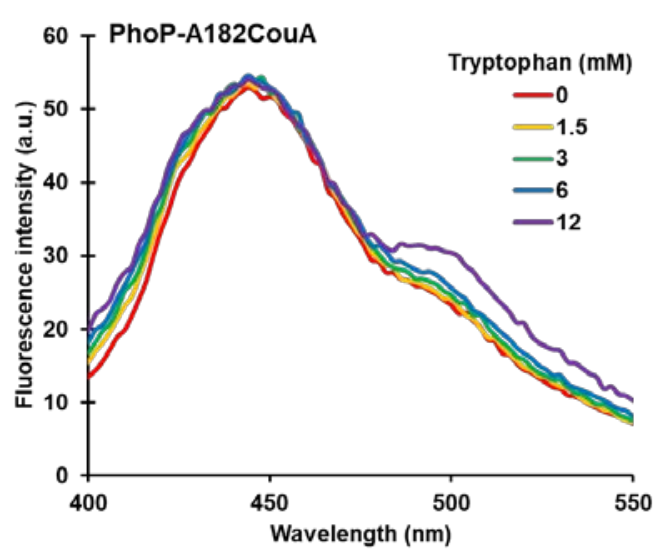

C

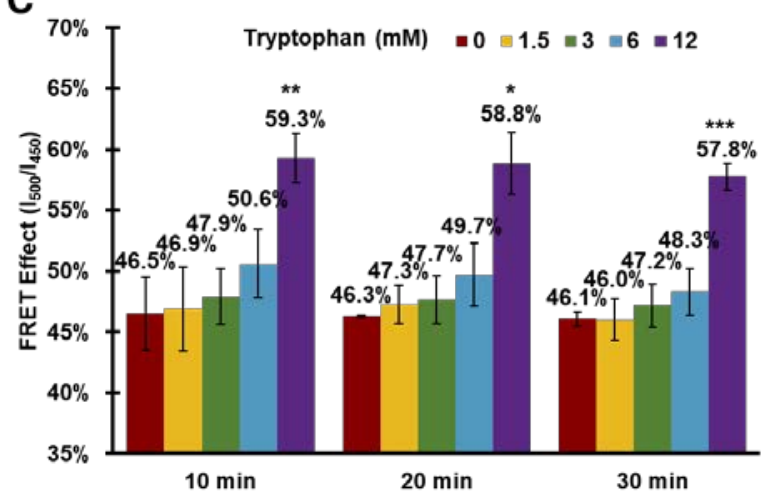

B

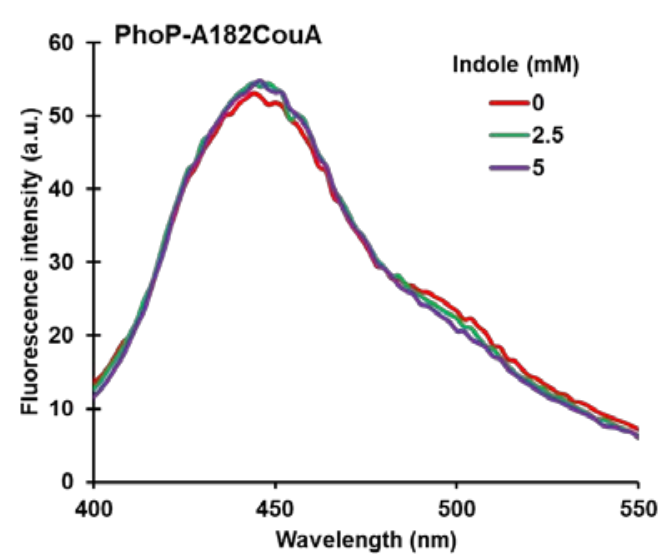

D

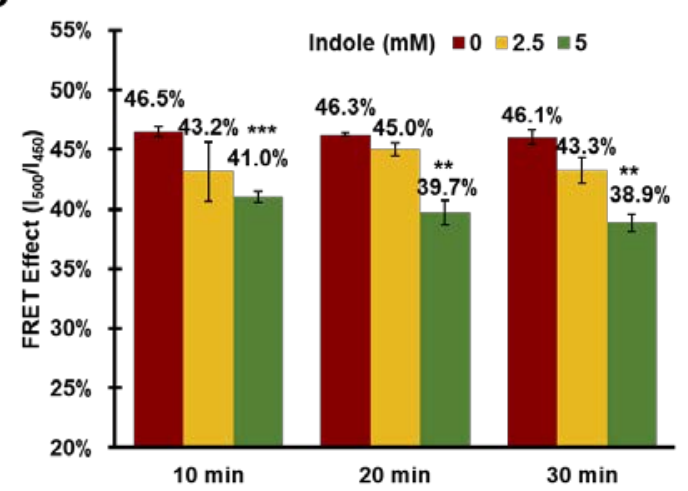

Figure 7. Intermolecular FRET-based assay system identifies new modulators of the PhoPQ system.

(A-B) Fluorescence spectra of BL21 (DE3) cells expressing PhoP-A182CouA (AY3709) in the presence of tryptophan (A), or indole (B). (C-D) FRET effect of assay mixtures under the designated conditions. Data are the mean of three biological repeats and are expressed as mean $\pm \mathrm{SD}$. ${ }^{*}, P<0.05$; ${ }^{\star *}, P<0.01$; ${ }^{\star \star \star}, P<0.001$ (based on Student's $t$ test). See also Figure S6 \& S7. 
bioRxiv preprint doi: https://doi.org/10.1101/2022.01.14.476424; this version posted January 15, 2022. The copyright holder for this preprint (which was not certified by peer review) is the author/funder, who has granted bioRxiv a license to display the preprint in perpetuity. It is made available under aCC-BY-NC-ND 4.0 International license.

A
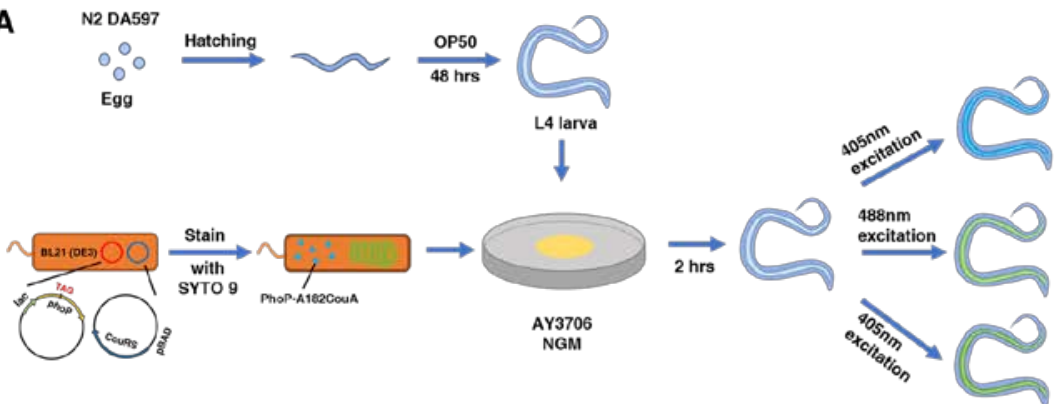

Em: $420-480 \mathrm{~nm}$ (CouA)

B

\section{C}
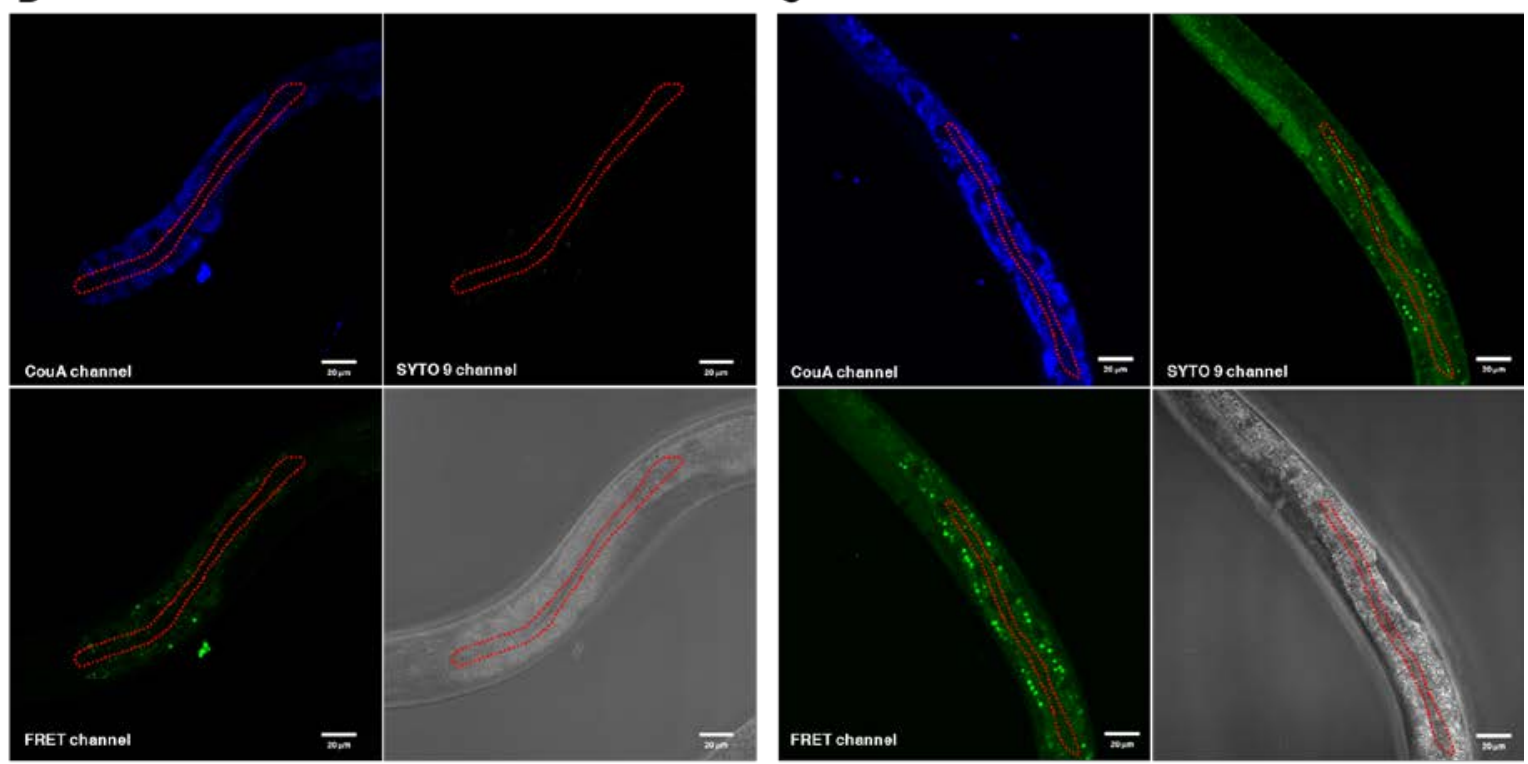

D
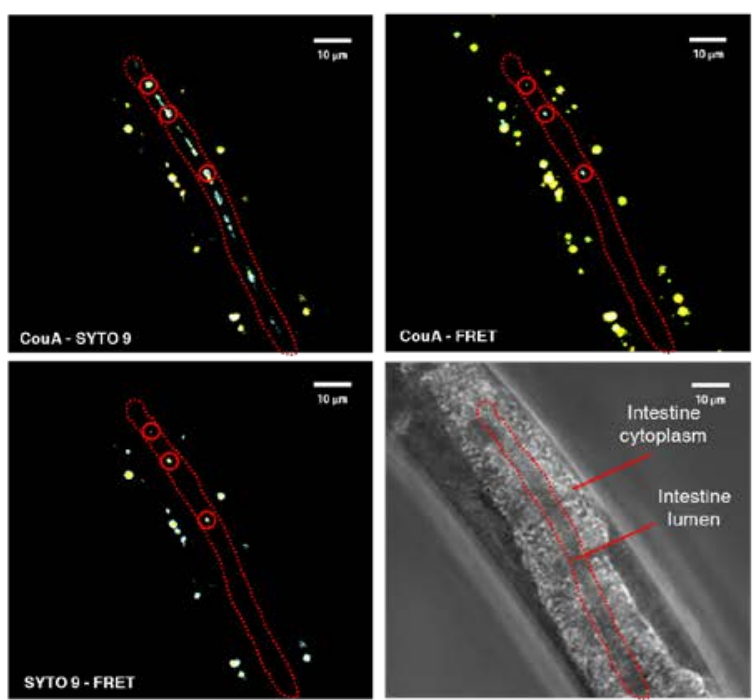
Figure 8. FRET measurement reports the PhoP-promoter activitiy in E. coli cells colonized in the $C$. elegans gut. (A) Workflow of the intermolecular FRET-based assay in the C. elegans colonization model. (B \& C) Fluorescence of $C$. elegans fed with OP50 (B) or BL21 (DE3) cells expressing PhoP-A182CouA (AY3709) (C) examined by confocal fluorescent microscope. Upper left: CouA emission fluorescence recorded in the range of $420-480 \mathrm{~nm}$ upon excitation at $405 \mathrm{~nm}$. Upper right: SYTO 9 emission fluorescence recorded in the range of $490-600 \mathrm{~nm}$ upon excitation at $488 \mathrm{~nm}$. Lower left: FRET signal recorded in the range of $490-600 \mathrm{~nm}$ upon excitation at $405 \mathrm{~nm}$. Lower right: Differential interference contrast (DIC) image of the $C$. elegans intestine area subjected to fluorescence recording. (D) Colocalization of different fluorescent channels in the intestine area of $C$. elegans in (C). Red circles indicate the colocalization between the indicated fluorescent channels. Upper left: CouA channel and SYTO 9 channel. Upper right: CouA channel and FRET channel. Lower left: SYTO 9 channel and FRET channel. Lower right: DIC image showing the intestine lumen and cytoplasm area. Red dash circles represent the intestine lumen region. See also Figure S5. 